\title{
LÓGICAS ESPACIALES CAMPESINAS EN LA ESTEPA PATAGÓNICA
}

\author{
ALBERTO D. VAZQUEZa
}

\begin{abstract}
RESUMEN
El artículo explora desde las lógicas espaciales las territorialidades de un amplio estrato de productores patagónicos que se distinguen por la condición de habitantes rurales. En base a antecedentes, fuentes históricas y tareas de campo, el análisis focaliza en movilidades extra-prediales a escala local y con sentido campo-campo o campo-localidad. Estas lógicas exhiben una tendencia decreciente en asociación con el declive ganadero que se profundizó desde la década de 1980. El análisis geo-histórico de las prácticas espaciales de un productor de la Meseta Central de Santa Cruz entre 1955 y 1991, exhibe dinámicas espacio-temporales en distintos escenarios familiares, técnicos y productivos, de un proceso que culmina con el éxodo rural familiar. Por último, se consideran otras lógicas relacionadas tanto al abandono y la pluriactividad como también a nuevas formas organizativas, reafirmaciones identitarias, defensas y reivindicaciones territoriales.
\end{abstract}

PALABRAS CLAVE: productor arraigado, lógicas espaciales, movilidades, éxodo rural.

\section{SPATIAL RURAL LOGICS IN PATAGONIAN STEPPE}

\begin{abstract}
This article explores, from the view of logical of spaces, the territoriality of a group of Patagonian producers distinguished by their condition of real rural residents. Based on previous studies, historical documents, interviews and observations, the analysis focuses on mobility's locally performed in direction countryside-countryside or countryside-locality (village or city). These logics show a decreasing tendency in association with the decline of livestock that deepened since the 1980s. The geo-historical study of spatial practices of a producer in the Meseta Central de Santa Cruz between 1955 and 1991 show spatial-times dynamic forces scenarios in different family, technical and productive situations, a process that ends with de rural family exodus. Last, other logics

a Grupo de Investigación Geografía, Acción y Territorio, Instituto de Investigaciones Geográficas de la Patagonia (GIGATIGEOPAT) - Departamento de Geografía, Facultad de Humanidades y Ciencias Sociales, Universidad Nacional de la Patagonia San Juan Bosco (UNPSJB). Km 4, (9000) Comodoro Rivadavia, Chubut, Argentina.

albertogeo85@gmail.com
\end{abstract}


are considered associated both to the abandon and plural activities such as new organization forms, identity reaffirmations, defense and territorial validation.

KEY WORDS: peasant, spatial logics, mobility, rural exodus.

\section{INTRODUCCIÓN}

En el marco del Programa de Investigación Transformaciones territoriales en la Patagonia central. Destinos de los espacios: análisis, discursos y prácticas ${ }^{1}$, el artículo presenta un análisis de las características que adoptan las territorialidades de los productores patagónicos en el contexto de los cambios culturales y económicos que son objeto de interés de los estudios rurales desde su resurgir en las últimas décadas del siglo $\mathrm{XX}$.

El análisis focaliza en las lógicas espaciales de los actores, es decir en las relaciones espaciales que producen mediante la demanda de bienes y servicios, la canalización de la renta y la construcción de lazos sociales y referencias culturales (Sili, 2007). La consideración de esas relaciones no sólo ha permitido la identificación de los rasgos propios del comportamiento espacial de los actores, evitando las territorialidades estáticas de las visiones dicotómicas de lo rural y lo urbano, sino también una aproximación analítica a la dinámica socio-cultural y económica de los territorios vivenciados por los mismos.

En este análisis se consideran las lógicas espaciales del productor de la explotación familiar, es decir de aquel productor que reside y trabaja de forma habitual en el campo, aquí denominado arraigado en oposición al absentista, y sus cambios en el contexto de las transformaciones contemporáneas.

Con este artículo se busca aportar al estudio de las transformaciones territoriales patagónicas con una lectura bidireccional del declive ganadero y el éxodo rural que contribuya al análisis del proceso de desestructuración de las áreas agroeconómicas marginales de la Patagonia argentina. Un proceso de desestructuración de los espacios rurales que se observa con claridad desde los años ochenta $y$ en los estudios regionales generalmente se

1 Programa de investigación de la Facultad de Humanidades y Ciencias Sociales de la UNPSJB, dirigido por el Dr. C. ha abordado desde la dimensión productiva, focalizando en la degradación de los suelos (desertificación) o en las consecuencias del nuevo ciclo político-económico.

Por lo tanto, los antecedentes de este tipo de estudios socio-territoriales en la Patagonia no son numerosos, se destacan los estudios de Andrade (2014) en la Meseta Central santacruceña, los de Bendini y Steimbreger (2011, 2013) tanto en la provincia de Neuquén como en la Línea Sur rionegrina y los de Comerci $(2010,2013)$ en el Oeste de La Pampa. Los aportes de los autores se recuperan en este análisis que, por el alcance espacial de la investigación en los ámbitos extra-andinos de Patagonia, involucra un conjunto más diverso de productores con el estudio de casos múltiples como estrategia metodológica.

Posteriormente alas precisiones metodológicas y conceptuales, el artículo se centra en el análisis de las lógicas espaciales de estos actores y su tendencia en el contexto de las transformaciones contemporáneas. Por último, se presenta un análisis geo-histórico en base a los registros diarios de una familia de la Meseta santacruceña, que muestra con nivel de detalle las lógicas espaciales de un productor a lo largo de la segunda mitad del siglo XX y sus variaciones en función de los distintos escenarios de un proceso que culmina con el éxodo rural familiar.

\section{EL ESTUDIO DE CASOS COMO ESTRATEGIA METODOLÓGICA}

La selección del estudio de casos múltiples como estrategia metodológica obedece a la amplitud empírica y conceptual del tema, a la insuficiencia de la información disponible para la realización de un abordaje más abarcativo y a la búsqueda de profundidad analítica desde una concepción del conocimiento que reconoce el valor de la complementariedad de los saberes provenientes de la epistemología del sujeto conocido y la

Santiago Bondel. 
epistemología del sujeto cognoscente (Vasilachis de Gialdino, 2006).

Los casos corresponden al tipo que algunos autores llaman paradigmáticos y otros mencionan como ejemplares o típicos (Marradi et al. 2010), pues la elección de los mismos se realizó con el foco puesto en las disimilitudes $y$ en las posibilidades que presenta cada caso para generar conocimiento acerca de las territorialidades de las poblaciones de interés. Tal como señalan Neiman y Quaranta (2006), en este tipo de estudios la muestra no depende de la cantidad para ser correcta como en los muestreos estadísticos, sino de su conformidad con la escisión temático-teórica.

En función de esos criterios se seleccionaron productores que poseen explotaciones ganaderas de diferentes tipos, pertenecientes a zonas rurales con diferentes niveles de desestructuración ante el declive del sector, que reúnen distintas condiciones de movilidad y se vinculan con localidades de diferente jerarquía. Por lo tanto, las tareas de campo se han distribuido espacialmente en diversos puntos de la Patagonia argentina (Fig. 1).

El trabajo de campo se dividió en dos etapas con acciones diferenciadas:

- en la primera etapa, se concretaron encuentros con informantes claves para el análisis exploratorio y la identificación de los casos.

- en la segunda etapa, se concretaron las entrevistas, la observación en terreno y otras acciones aisladas como ejercicios de cartografía social.

Las entrevistas fueron semi-estructuradas con preguntas que giraron en relación a los vínculos en el área rural y con las localidades, los motivos de los desplazamientos y las características de los mismos, el éxodo rural y los cambios en las relaciones socio-territoriales.

La observación tradicional se ha complementado con instancias de observación participante en reuniones y talleres, es el caso de una asamblea de la comunidad mapuche Newen Nuque Mapu celebrada en el paraje Cañadón Chileno por conflicto de tierras (enero de 2014) o de los talleres desarrollados en la localidad Alto Río
Senguer en relación a la accesibilidad a la salud de poblaciones rurales (septiembre de 2013).

El trabajo de campo se ha complementado con la revisión de los antecedentes bibliográficos y de las estadísticas disponibles y con un análisis espacial-cartográfico en base a fuentes históricas de la segunda mitad del siglo XX (Figs. 2 y 3).

Los registros diarios de la familia Moyes en la estancia San Agustín entre 1955 y 1991, propician el análisis de las rupturas en la evolución histórica de las prácticas espaciales de un productor de la Meseta santacruceña, un análisis que se apoya en el uso de sistemas de información geográfica y se realiza considerando los diferentes contextos técnicos, familiares y productivos. El tratamiento de la información de los registros referida a desplazamientos y permanencias extraprediales del productor, ha seguido los siguientes pasos:

en primer lugar, se identificaron los recorridos de los desplazamientos para crear tres coberturas espaciales de datos vectoriales con el software Qgis 2.10: a) destinos de los desplazamientos, b) caminos transitados, y, c) desplazamientos lineales. Las coberturas se crearon con el sistema de coordenadas Gauss Krüger (en la faja 2) y el datum geodésico WGS84, en base a: la información espacial del Instituto Geográfico Nacional (IGN), un mosaico de imágenes satelitales y la colaboración de antiguos pobladores para la identificación de sitios no identificables desde la observación $y$ de sitios que en los registros aparecen con denominaciones genéricas (ej. el cruce), números de lote (ej. el 18) o apellidos de personas (ej. lo de Segovia);

- en segundo lugar, se sistematizaron los datos en dos tablas, una organizada en función de los recorridos y con la cantidad anual de desplazamientos como indicador y otra organizada en función de los lugares de destino y con la cantidad de días con presencias del productor como indicador;

- en tercer lugar, se incorporaron las coberturas espaciales y las tablas al software Qgis 2.10 para el procesamiento de la información y la elaboración de dos mapas temáticos, uno de tipo cualitativo y otro de tipo cuantitativo 




Fig. 1. Las tareas de campo en la Patagonia Argentina. Fuente: elaboración propia. 

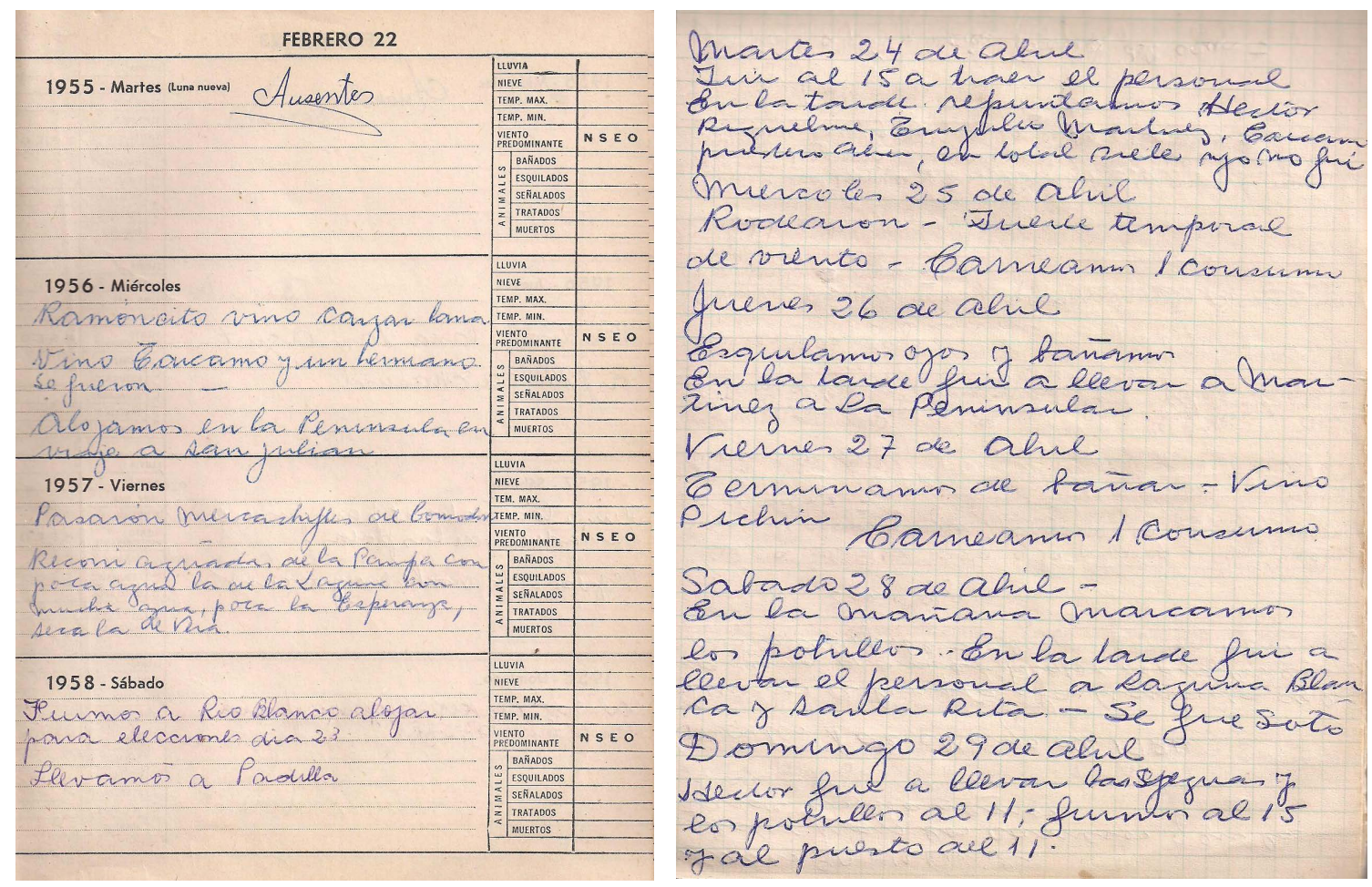

Figs. 2 y 3. El dato en los cuadernos de anotaciones diarias de la familia Moyes, 1955-1958 y 1984.

compuesto de vistas anuales representativas de los diferentes comportamientos espaciales del productor a lo largo de la etapa;

en cuarto lugar, se recuperó la información correspondiente a dos años en los extremos del período de registro para representar los comportamientos espaciales del productor en tiempos más cortos (días, meses y estaciones), adaptando los dioramas ideados por Hägerstrand.

\section{LOS ESPACIOS DE LAS LÓGICAS: ASPECTOS GENERALES DE SU ORGANIZACIÓN}

Las configuraciones geográficas de la Patagonia son especialmente el resultado del proceso de ocupación y organización de la ganadería ovina extensiva. La base de la ocupación ganadera de las tierras fue un parcelamiento en forma de cuadrícula, fórmula simple y operativa en estas vastas extensiones conquistadas que el comando centralizado en el parlamento nacional percibía desérticas y homogéneas (Randle, 1972).
Con ese parcelamiento, desde las últimas décadas del siglo XIX se originó una estructura rural donde, fuera de unas pocas colonias exitosas, lo prototípico fue el latifundio empresarial, la estancia familiar y el minifundio marginal (Bondel \& Vazquez, 2013).

La funcionalidad asociada a esa estructura rural ganadera fue el origen de parajes, pueblos y ciudades que, distribuidos de forma dispersa en una extensión que sólo en el escenario de análisis alcanza más de $1 / 5$ de la superficie nacional, componen un rasgo característico de la organización espacial patagónica. Coronato (2010) refiere a la modalidad de surgimiento en oposición a la modalidad de fundación en una zona desocupada y destaca diferencias intraregionales para el caso patagónico: La mayoría de los núcleos fundados se encuentran en el norte de la Patagonia y muchos de ellos son el fruto de los fortines establecidos durante la campaña militar de 1879-84. Los núcleos surgidos, en cambio, son más frecuentes en el sur y son el resultado del avance del frente pionero del sur (2010, pp. 92-93). 
La distribución espacial de esos asentamientos que en buena medida surgieron en relación a un puerto, una posada/ almacén de ramos generales (boliche), una escuela o una estación ferroviaria, se asocia a las formas que adquirieron los vínculos espaciales de los actores rurales. Al sur del Valle Medio del río Chubut es mayor la dispersión de las localidades, en especial al interior de la extensa Meseta Central de Santa Cruz, donde es gravitante el influjo de localidades de la costa atlántica, el norte de la provincia homónima y el sudeste de Chubut. En cambio al norte, coincidiendo con la mayor concentración de poblaciones campesinas, existe un número significativo de pequeñas localidades, en su mayoría parajes y pueblos que en la Meseta no superan los 1.000 habitantes. Esas localidades funcionan con el influjo de otras de mayor jerarquía y de los centros urbanos regionales, integrando un sistema sin metrópoli regional y con subsistemas embrionarios, de escasa o nula interacción y articulación entre ellos (Erbiti, 1996, p. 117).

La creación de condiciones para la mayor circulación de personas, productos, dinero, información y órdenes es una característica del período actual (Silveira, 2009). Los avances en relación a objetos y sistemas de ingeniería generan mejoras en la conectividad y consecuentemente en la articulación regional. El ejemplo más evidente es el avance del pavimento en rutas como la $\mathrm{N}$ 40, la P 27-288 de Santa Cruz y la N 23 de Río Negro. Las mejoras en la conectividad física de las áreas rurales se producen de forma indirecta en el marco de procesos selectivos de creación de fluidez asociados a la integración del sistema urbano y/o la demanda de sectores económicos modernos (Silveira, 2009, p. 444), o con acciones públicas que especialmente en la última década se concretaron en territorios rurales con predominio de campesinos.

Las políticas dirigidas a mejorar la conectividad de los territorios rurales, por ejemplo en Chubut, se materializaron en una significativa cantidad de pasarelas y puentes de hormigón (en total más de cuarenta) (Fig. 4). Es ilustrativo el caso del puente construido sobre el arroyo Chalía con implicancias positivas en las condiciones de movilidad y la integración de la comunidad homónima. Gatica (2006) señala esas implicancias al considerar las condiciones de aislamiento que, con origen en las crecidas del arroyo, vivenciaban los campesinos de la margen sur. Por otra parte, entre las mejoras en la conectividad virtual se destacan aquellas con origen en los equipos de radio instalados en comunidades y en los escasos derrames de conectividad desde las antenas de telefonía celular emplazadas en las localidades o desde las antenas de internet satelital que en el marco del Plan Nacional de Telecomunicaciones: Argentina Conectada y con las dificultades propias de acciones embrionarias proveen del servicio a las escuelas rurales.

...vino Fomicruz y por dos piedras (con el comentario refiere al proyecto minero Pórfido Santa Cruz) arreglaron el camino; siempre nos arreglamos como podíamos, poniendo piedras en los zanjones (cárcavas)... (Productor de la zona de Bajo Caracoles, Santa Cruz, febrero de 2011).

...la escuela tiene internet porque se está dando clases de secundario por medio virtual, es la primera promoción, son 20 chicos más o menos, y eso se está dando en varios parajes, está bueno porque antes se iban a Norquinco (...), algunos productores que habitan cerca de la escuela tienen computadora y podés mandarle un mail (Extensionista del Instituto Nacional de Tecnologías Agropecuarias (INTA) en el Paraje Río Chico, Río Negro, enero de 2014).

Hay un puesto sanitario, hay una escuela, hay un equipo de radio que depende de defensa civil de la provincia, asique estamos bastante comunicados, el tema del camino no, pero es un pedido que venimos haciendo por muchos años, es un lugar bastante complicado para poder hacer los caminos, hay muchos cerros, muy altos y para hacer el cambio de un camino hay que hacer un estudio bastante amplio y saber cómo hacerlo; ahora con la sequía no hay problema, pero en años nevadores en Anecón no se podía entrar 


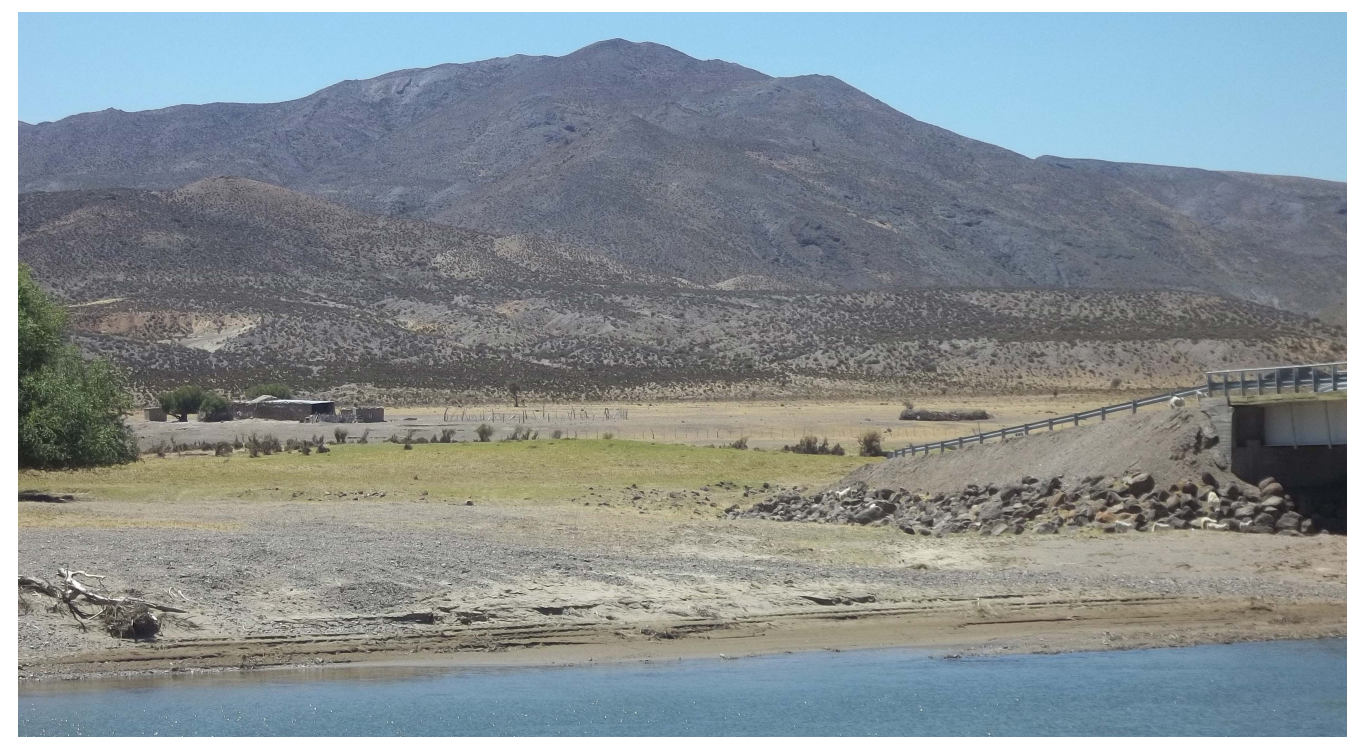

Fig. 4. Puente sobre el río Chubut en el paraje Gorro Frigio; como en otros casos con efectos trascendentes en la dinámica espacial. Fuente: fotografía del autor, enero de 2015.

hasta el mes de noviembre... (Miembro de la comunidad Anecón Grande, Río Negro, enero de 2014).

\section{LÓGICAS ESPACIALES Y PRODUCTORES}

Las lógicas espaciales de los actores rurales han sido abordadas desde la movilidad, pues la movilidad excede al mero desplazamiento físico de personas $\mathrm{u}$ objetos $\mathrm{y}$ produce esas relaciones espaciales que pueden ser analizadas desde las dimensiones culturales, económicas y políticas (Benedetti \& Scalizzi, 2011).

En función de la movilidad de los actores se han diferenciado dos grandes tipos de lógicas espaciales:

a) lógicas campo - localidad, es decir lógicas de actores que residen en establecimientos rurales y con cierta frecuencia se desplazan a las localidades, $y$;

b) lógicas localidad - campo, es decir lógicas de actores que residen en localidades con distintos tamaños/jerarquías y con una determinada frecuencia se desplazan al campo.

Estas lógicas también se distinguen considerando las escalas definidas por la extensión de las redes de movilidad en un marco geográfico patagónico de extensas superficies rurales y dispersión de localidades. La Tabla 1 muestra las características de los desplazamientos en cada una de esas escalas.

Los actores rurales, entonces, han sido clasificados a partir de sus lógicas espaciales y agrupados bajo denominaciones adoptadas de los antecedentes académicos o los documentos oficiales y otras propuestas en este artículo.

En los estudios regionales regularmente se ha utilizado el término absentistas (o ausentistas) para denominar a aquellos actores que disocian el espacio residencial del espacio productivo, construyendo sus vínculos principalmente en el mundo urbano. $Y$ en estudios recientes se han introducido otras categorías, tal es el caso de la categoría actores invisibles introducida por Neira y Torres (2012) para denominar a los actores más ausentes (citado en Sáenz Passeron, 2015).

Por su parte, el grupo de actores con lógicas espaciales campesinas no ha sido agrupado en la bibliografía bajo una única categoría. Si bien en su significado más amplio la categoría de campesino representa al conjunto de los productores que viven y trabajan en el campo, en su significado más restringido excluye a un grupo numeroso de productores con lógicas campo-localidad, pues el 
Tabla 1. Escalas de las lógicas espaciales. Fuente: elaboración propia en base a tareas de campo.

\begin{tabular}{lll}
\hline Escalas de las lógicas espaciales & $\begin{array}{l}\text { Tiempo de desplazamiento } \\
\text { establecimiento - localidad (horas en } \\
\text { medio de transporte más frecuente). }\end{array}$ & Lugar de residencia principal \\
\hline Local & Menos de 5 horas en automóvil. & $\begin{array}{l}\text { Campo } \\
\text { Localidades de la zona (parajes, pueblos } \\
\text { y ciudades). }\end{array}$ \\
\hline Regional & Entre 5 y 15 horas en automóvil. & $\begin{array}{l}\text { Localidades de la región (principalmente } \\
\text { centros urbanos regionales). }\end{array}$ \\
\hline Transnacional & Más de 6 horas en avión + automóvil. & $\begin{array}{l}\text { Centros urbanos, fuera de la región y en } \\
\text { el país. }\end{array}$ \\
\hline
\end{tabular}

significado dado a la categoría en América Latina tiene componentes socio-económicos y culturales (incluso étnicos) tan significativos como la propia espacialidad. Tal como lo entiende Tsakoumagkos (2014), el problema es la conceptualización de un grupo de productores con explotaciones donde la combinación trabajo familiar/capital es diferente a las de los campesinos, un grupo que se ha definido con diversas denominaciones empíricas (colono y chacarero, entre otras) y en la Patagonia se ha incluido en categorías que encierran actores con diversas espacialidades, por ejemplo ganadero o estanciero, simplificando el complejo universo de actores en una dicotomía que regularmente se expresa en la dualidad criancero o ganadero $y$, bajo criterios más amplios, en la dualidad campesino o estanciero.

Entre las categorías incorporadas en los últimos años, la noción Agricultura Familiar definida en el FONAF (2006) representa a este último grupo de actores. No obstante, la categoría EAP familiar, generada por Scheinkerman de Obschatko (2009) para otorgarle operatividad a esa noción en la Argentina, no resuelve el problema conceptual. Si bien las explotaciones de todos estos productores cuentan con las características requeridas para ser consideradas explotaciones familiares (el trabajo del productor y un máximo de dos empleados), los límites en la extensión del establecimiento (no más de 5.000 has) y en la cantidad de ganado (no más de 500 animales de cualquier tipo) excluyen de la categoría a numerosas explotaciones. El desatino de los límites es notorio incluso en los argumentos que se presentan a continuación, pues en la Patagonia existen campos de más de 20.000 hectáreas y con más de 2.000 ovinos, explotados familiarmente y con no más de un trabajador permanente.

...para evitar que se filtraran en el universo explotaciones que, con toda evidencia, no pueden ser explotadas principalmente con una estructura de trabajo familiar -aun incorporando dos trabajadores no familiarespero que, por cuestiones de declaración censal, pudieran aparecer como tales... (Scheinkerman de Obschatko, 2009, p. 10).

Por lo tanto, ante la ausencia de un concepto que defina a este universo de actores con lógicas espaciales campo-localidad, se incorpora la denominación de productores arraigados. Estos son productores con explotaciones que generalmente reúnen las siguientes características:

- fuerza de trabajo familiar (al menos del productor), exclusivamente o con un empleado permanente;

- escalas de producción que en la actualidad permiten escaso nivel de capitalización o determinan economías de subsistencia e incluso por debajo de la línea de subsistencia;

- sistemas productivos predominantemente ovinos y mixtos (ovinos-caprinos);

- tenencia de la tierra con diferentes figuras legales, de modo individual/ familiar o comunitario;

- establecimientos con superficies que en los casos identificados oscilan entre 600 y 20.000 hectáreas. 


\section{LAS LÓGICAS ESPACIALES EN LA MOVILIDAD DE LOS PRODUCTORES ARRAIGADOS}

En estos espacios patagónicos donde las nuevas tecnologías de comunicación todavía tienen un impacto muy restringido a modo de enclaves de conectividad, las relaciones son esencialmente el producto de la movilidad de los propios productores o de familiares, conocidos, mercachifles (comerciantes ambulantes) y personal de instituciones con incumbencias en el medio rural (cooperativas, organismos del sector agropecuario, hospitales, etc.), entre otros actores que experimentan los espacios dispersos ocasionando el cruce de territorialidades.

Teniendo a la dispersión como rasgo característico de la organización espacial, la movilidad es parte de las acciones cotidianas del productor. La movilidad se compone de los desplazamientos prediales habituales desde el espacio doméstico y peri-doméstico al campo (Comerci, 2010, p. 86), y de los desplazamientos extra-prediales en el medio rural disperso o hacia las localidades (Fig. 5). La movilidad extra-predial toma diferentes formas, el uso del caballo es típico entre las poblaciones campesinas y existe una gran dependencia del automóvil en función de las distancias. La disponibilidad de un vehículo automotor es común entre productores con cierto grado de capitalización y ante su ausencia se despliegan estrategias como la colaboración entre vecinos, la asistencia de habitantes urbanos -familiares o conocidos- y la combinación de formas de movilidad. Esta última, que desde campos próximos a rutas principales consiste en la realización de tramos a caballo o a pie y otros en transportes colectivos de pasajeros ${ }^{2}$ o en vehículos

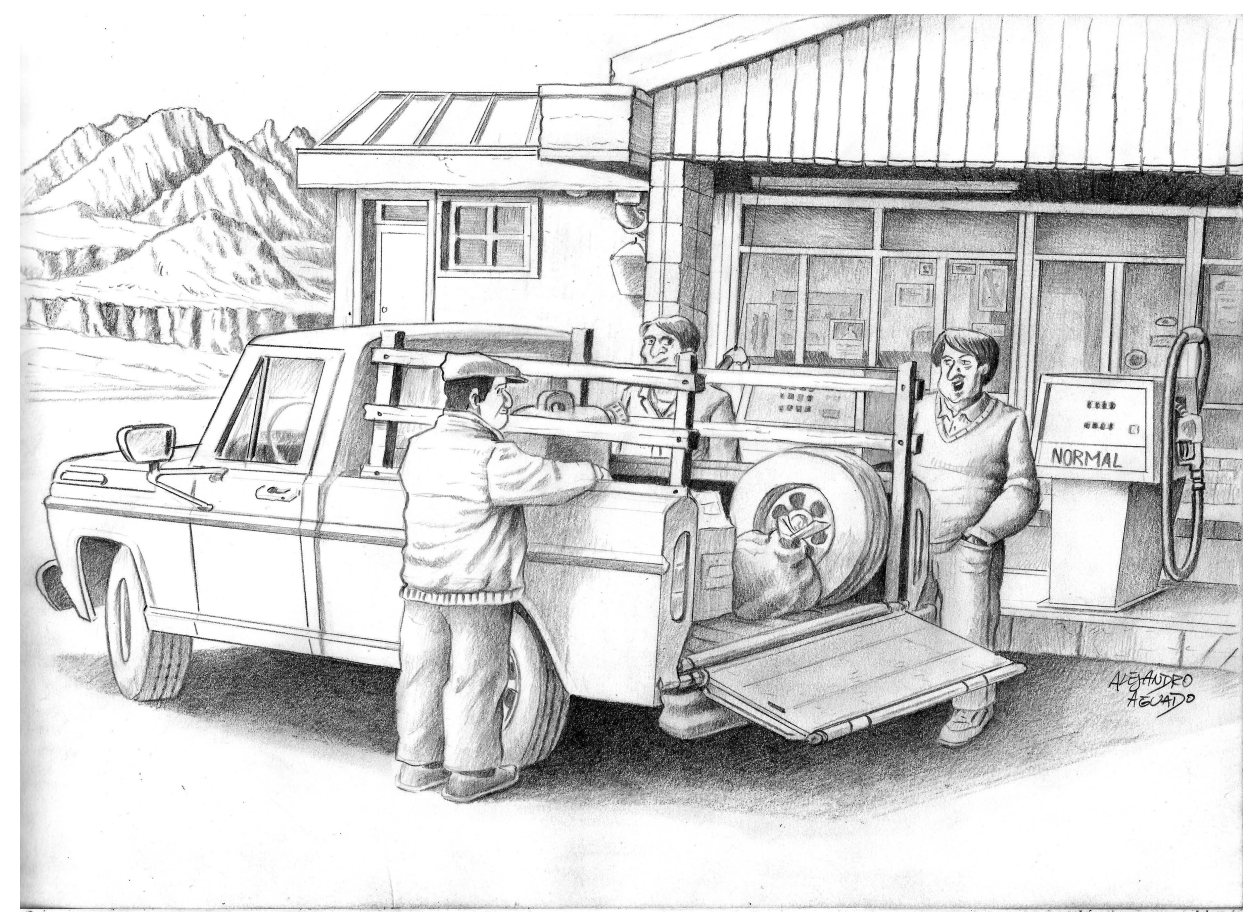

Fig. 5. Visión iconográfica de un reconocido comunicador regional, típica escena de la movilidad de un arraigado. Fuente: dibujo de Alejandro Aguado.

2 Cabe destacar que en casos de insostenibilidad económica del servicio, su continuidad depende de subsidios. Así lo indica un hecho reciente y de resonancia mediática como fue la cancelación en el mes de enero del servicio de transporte de pasajeros que con frecuencia semanal une las pequeñas localidades de Ricardo Rojas, Aldea Beleiro,
Río Mayo y Lago Blanco, con la ciudad de Comodoro Rivadavia y los ámbitos rurales dispersos del recorrido (Diario El Patagónico, http://www.elpatagonico.com/ lago-blanco-no-contara-servicio-transporte-publico-elinvierno-n1476667, visitada el 21 de marzo de 2016). 
de particulares en viaje, surge por ejemplo del testimonio de un productor de El Chalía:

Yo nací acá y sigo acá, fui a la escuela de a caballo nomás, pero ahora esa escuela se cerró; teníamos la escuela acá en la comunidad, pero cuando se hizo el internado de Río Mayo ahí ya mandaron todos los chicos para allá (...). Acá la jurisdicción para sacar permiso de señalada y todo eso es Ricardo Rojas; cada tanto voy, pero voy y vuelvo en el día, por ahí cuando tengo alguna necesidad o cuando tengo que comprar, sino no voy (...). Cuando voy a Ricardo Rojas voy de a caballo hasta la ruta; algún vehículo siempre me levanta, y el caballo lo dejo en el callejón, está todo cerrado, no sale el caballo, y de vuelta lo paso a buscar (...) Y voy una vez al mes, más o menos, (...). Yo estoy siempre acá, uno se acostumbra. Ahora la mayoría tiene jubilación, eso ayuda bastante porque acá plata no gastás, acá se compra una sola vez en el año nomás... (julio de 2015).

\section{Lógicas espaciales campo-campo}

La movilidad en el medio rural es acorde al tejido de relaciones de confianza, reciprocidad y cooperación considerado capital social (Durston, 2000 , p. 7). Los motivos más frecuentes de los desplazamientos van desde las visitas corrientes en el marco de relaciones de vecindad, amistad o parentesco, hasta la cooperación en tareas agropecuarias o en situaciones propias de la vida en el campo. No obstante, Durston (2000) advierte que las relaciones en el medio rural son complejas pero no necesariamente densas como surge de las miradas que idealizan la vida en el campo. Ese tejido de relaciones se debilitó con los procesos de éxodo rural, se sostiene en áreas poco desestructuras ante las transformaciones $y$ es especialmente denso en comunidades de pueblos originarios por la coexistencia de aspectos materiales, funcionales y simbólicos. Durston (2000) sostiene que en patrones de asentamiento disperso el espacio social es afectado por el espacio material, en se sentido tanto en el caso de las reservas indígenas como en las zonas de predominio minifundista las relaciones son propiciadas por lo material, pues el tamaño de las parcelas es menor y los espacios de algunas comunidades contienen objetos de uso común: tierras de posesión comunitaria, medios de comunicación y/o instalaciones (Fig. 6).

Para esquilar suelen ir a lo de un vecino que tiene un mejor galpón, o no, algunos se agrupan y hacen la esquila juntos... (Agente en salud comunitaria del hospital rural de Alto Río Senguer en relación a la comunidad Tramaleo, Chubut, septiembre de 2013).

Ahora en la comunidad pusieron un radio teléfono por cualquier cosa y ese está ubicado en lo de __ sobre la ruta 40 y también hay transmisores, pero solamente se comunican cuando es algo que necesitan... (Miembro de la comunidad Tramaleo, Oeste de Chubut, septiembre de 2013).

...se esquila en el galpón comunitario, como la máquina está ahí, vienen esquiladores (...). En el puesto sanitario nunca hay nadie, el galpón comunitario por ahí tiene más salida, ahí viene la doctora a lo lejos, seguido vienen enfermeras... (Miembro de la comunidad El Chalía, SO de Chubut, julio de 2015).

Los desplazamientos campo-campo asociados al trabajo extra-predial del productor o de sus hijos son comunes entre los minifundistas. Las contrataciones son por día, especialmente para los trabajos (esquila, esquila de ojos, señalada, destete y baño), o de forma mensual como puestero en establecimientos mayores. Cabe destacar que la disponibilidad de fuerza de trabajo es considera una de las motivaciones que impulsó la creación de reservas y la consecuente imposición a nómadas sobrevivientes a las campañas militares de una lógica espacial zonal: mediante una circulación controlada el objetivo era que se vuelvan peones rurales semi-sedentarios avocados a 


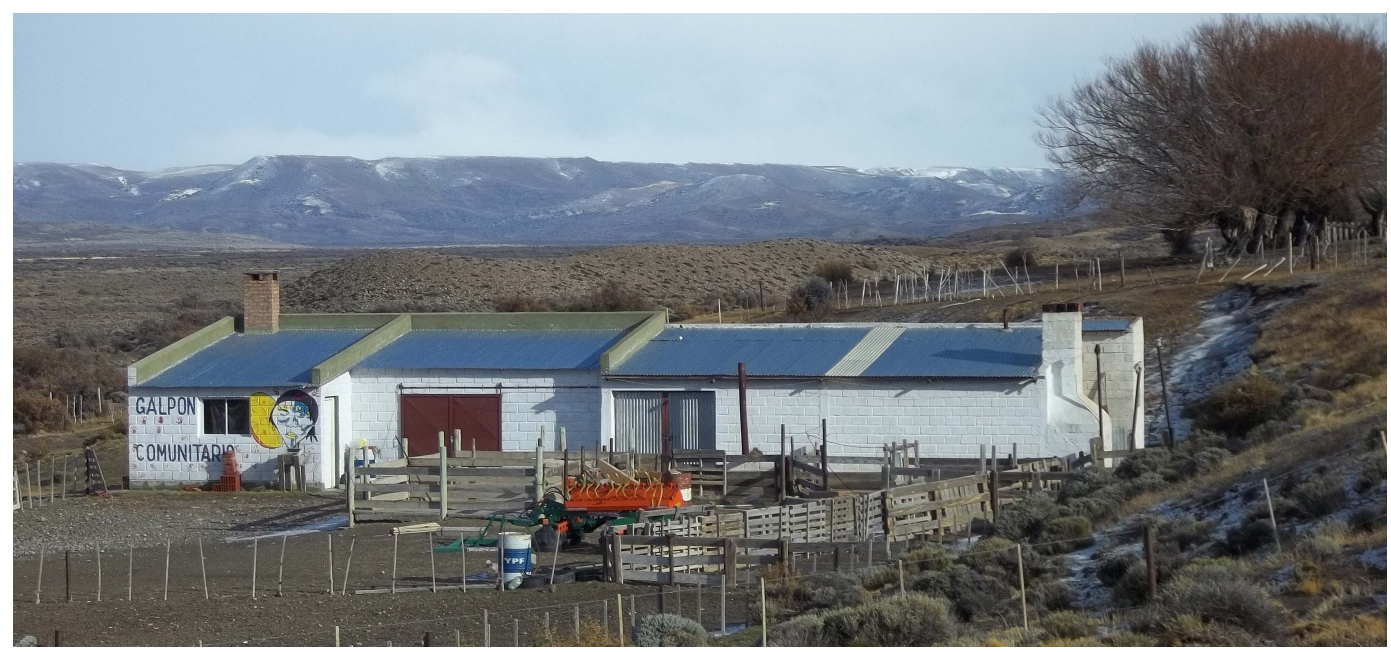

Fig. 6. Galpón de esquila de El Chalía, de propiedad y gestión comunitaria. Fuente: fotografía del autor, julio de 2015.

tareas estacionales (Rodríguez, 2010, p. 20). Es evidente entonces que estos comportamientos no son novedosos, como tampoco lo es el éxodo a otros espacios rurales o urbanos desde posesiones comunitarias o familiares donde el tamaño de la unidad funcional es insuficiente para la convivencia generacional y la reproducción social. En la actualidad es habitual que poblaciones con origen en zonas de predominio campesino trabajen incluso a cientos de kilómetros en grandes estancias de la Patagonia austral. Las entrevistas dan cuenta del alcance de esta condición entre los minifundistas del norte regional y en los enclaves campesinos de la Patagonia central:

Acá en la zona también hay grandes estancias, mucha diversidad, algunos minifundistas son empleados en otros establecimientos... (Técnicas de la Cooperativa De Vuelta Al Campo, enero de 2014)

...Tramaleo llegó a tener 16 leguas de campo en Loma Redonda, a $7 \mathrm{~km}$ de acá $y$ se vino, puso el rancho y una quintita porque estaba la escuela, y la escuela estaba acá porque estaba la ruta y el boliche (...). Vos tenés todo un paisanaje acá y la estancia que necesita mano de obra viene acá, esa es la lógica (Miembro de la comunidad Tramaleo, Oeste de Chubut, octubre de 2015). ...de casualidad por ahi la gente trabaja en las estancias en pelada de ojos, esquila, pero después que pasa la campaña ya no hay trabajo... (Miembro de la comunidad El Chalía, Chubut, julio de 2015).

La relación con las estancias de la zona bien, por ejemplo tenés a _que es puestero en La Paloma y tiene su casa en El Cordón, también el nieto del que era el cacique; las estancias ocupan la misma gente de la zona, ya sea por día o estable; entonces algunos tienen parcela y ganado y también trabajan en la zona, ellos o sus hijos (Agente en salud comunitaria en relación a la comunidad Tramaleo, Chubut, septiembre de 2013).

Excepcionalmente la movilidad en el medio rural es el producto de la explotación y/o tenencia de más de un establecimiento. Los establecimientos en producción habitualmente están integrados en términos funcionales y cuando implican sitios ante-cordilleranos y cordilleranos a partir de un manejo rotativo con alternancia estacional del pastoreo que presenta analogías y diferencias con la trashumancia neuquina. Entre los casos identificados en la estepa se destacan aquellos donde la movilidad se produce entre establecimientos linderos o en la zona con motivos productivos o asociados al cuidado/mantenimiento de establecimientos sin producción. 
...esos campos no son para tener vacas, lo que pasa es que allá arriba los campos son patria, meten las vacas en alguna estancia $y$ después las vacas andan por todos los campos de la zona (...) como total están abandonados. A le prestaron o alquilaron tres o cuatro campos, dos están pegados y el otro más lejos, y ahí metió las vacas, él vive ahí y tiene que andar atrás de las vacas (Antiguo productor de la zona de Bajo Caracoles, Santa Cruz, enero de 2011).

...en La Irene no tienen animales, ella vive en Cerro la Esperanza que es del esposo, ahí deben tener unos 400 animales... (Técnicas de la Cooperativa De Vuelta Al Campo, enero de 2014)

\section{Lógicas espaciales campo-localidad}

Los vínculos espaciales y sus escalas son indicadores de la heterogeneidad estructural del complejo universo rural patagónico. Los productores arraigados tienen un comportamiento espacial local, pues sostienen fuertes vínculos con localidades cercanas que indiferentemente de su jerarquía en el sistema urbano cumplen roles de importancia en función de las distancias y sus condiciones técnicas de movilidad. Así lo indican los patrones de distribución de las localidades en zonas con predominio de poblaciones campesinas y los propios entrevistados:

... la gente se aprovisiona para todo el año completo, o sea la mayoría son socios de la Cooperativa Ganadera Indigena y hacen el pedido durante el año, después el caso de combustible, en el caso de Anecón hay un paraje ahí cerquita que es Onelli, de ahi a $35 \mathrm{~km}$ hacia el Sur queda la escuela, el puesto sanitario y todo (...). Jacobacci es el centro de las comunidades, vienen a proveerse acá, algunos tienen familiares, pero otros vienen más que nada a comprar, porque en los parajes es mucho más caro, entonces depende de la distancia, y si tienen medio de movilidad o no (Consejero de la Línea Sur rionegrina por el Consejo de Desarrollo de las Comunidades Indígenas, enero de 2014).

Los minifundistas de los alrededores casi todos se vinculan con Paso de Indios, hay casos en los que viven en el campo y casos en los que viven acá y van cada tanto, o queda alguien en el campo y la familia vive acá (...). Los productores grandes y medianos la mayoría vive en Trelew y acá tienen peones, vienen para la esquila o trabajos puntuales nomás (Técnica de la cooperativa De Vuelta Al Campo enero de 2015).

La movilidad campo-localidad presenta una gran diversidad en sus características. La Tabla 2 contiene casos representativos y simplifica dinámicas espaciales irregulares que en zonas pueden contener una marcada estacionalidad, en frecuencias y estadías aproximadas. Las frecuencias en los desplazamientos en casos son de una o dos veces al mes con estadías que no suelen superar los dos días y en otros son mayores o incluso menores. La diversidad se asocia a factores de alcance general y a situaciones de tipo familiar/personal. Factores de incidencia destacada son la distancia entre el establecimiento y las localidades con primacía en las lógicas espaciales del productor; el grado de capitalización que determina la disponibilidad tanto de medios de transporte como de lugar donde alojar, el tipo de explotación (individual/familiar, con/sin personal) y circunstancias personales como acceso a servicios, cobro de pasividades y temas afectivos.

Los flujos simplificados en la Tabla 2 generalmente son multipropósito y presentan variaciones cuando responden a motivos específicos; esas variaciones se observan, por ejemplo, en la movilidad asociada a los servicios de salud. En un ejercicio de Cartografía Social en el hospital rural de Alto Río Senguer y en relación al acceso a la salud de los habitantes de Loma Redonda y Pastos Blancos (comunidad Tramaleo), se dibujan recorridos, formas de movilidad y obstáculos. En parcelas de residencia individual o familiar y con predominio de adultos mayores, las tierras de la comunidad son habitadas por unos 40 pobladores (Planillas de relevamientos sanitarios, 2013) que acceden a 
Tabla 2. Casos representativos de los desplazamientos campo-localidad de productores arraigados.

Fuente: elaboración propia a partir de tareas de campo.

\begin{tabular}{|c|c|c|c|c|c|c|}
\hline $\begin{array}{l}\text { El actor } \\
\text { (casos) }\end{array}$ & $\begin{array}{l}\text { Residencia en } \\
\text { el est. }\end{array}$ & $\begin{array}{l}\text { Localidades } \\
\text { de primacía } \\
\text { en las lógicas } \\
\text { espaciales }\end{array}$ & $\begin{array}{l}\text { Distancia } \\
\text { aproximada }\end{array}$ & $\begin{array}{l}\text { Forma } \\
\text { frecuente de } \\
\text { movilidad }\end{array}$ & $\begin{array}{l}\text { Frecuencia y } \\
\text { estadía en las } \\
\text { localidades }\end{array}$ & La explotación \\
\hline $\begin{array}{l}\text { Productor } \\
\text { tradicional de } \\
74 \text { años }\end{array}$ & Única familiar & $\begin{array}{l}\text { Comallo } \\
\text { (1.498 hab.) }\end{array}$ & $\begin{array}{l}60 \mathrm{~km} \text { (caminos } \\
\text { y rutas de ripio) }\end{array}$ & $\begin{array}{l}\text { Vehículo de } \\
\text { familiares o } \\
\text { conocidos }\end{array}$ & $\begin{array}{l}\text { Mensual, estadías } \\
\text { que se limitan al } \\
\text { día }\end{array}$ & $\begin{array}{l}\text { Minifundio } \\
\text { ganadero en } \\
\text { producción }\end{array}$ \\
\hline $\begin{array}{l}\text { Productor } \\
\text { tradicional } \\
\text { de aprox. } 40 \\
\text { años }\end{array}$ & Única familiar & $\begin{array}{l}\text { C. Onelli } \\
\text { (114 hab.) } \\
\text { Ing. Jacobacci } \\
\text { (6.261 hab.) }\end{array}$ & $\begin{array}{l}40 \mathrm{~km} \text { y } 90 \mathrm{~km} \\
\text { (camino vecinal y } \\
\text { rutas de ripio) }\end{array}$ & $\begin{array}{l}\text { Vehículo } \\
\text { personal }\end{array}$ & $\begin{array}{l}\text { Cada quince días, } \\
\text { estadías que se } \\
\text { limitan al día o de } \\
\text { dos días }\end{array}$ & $\begin{array}{l}\text { Minifundio } \\
\text { ganadero en } \\
\text { producción (tierras } \\
\text { comunitarias) }\end{array}$ \\
\hline $\begin{array}{l}\text { Productor } \\
\text { tradicional } \\
\text { de aprox. } 68 \\
\text { años }\end{array}$ & $\begin{array}{l}\text { Única } \\
\text { individual }\end{array}$ & $\begin{array}{l}\text { Ricardo Rojas } \\
\text { (219 hab.) }\end{array}$ & $\begin{array}{l}30 \mathrm{~km} \text { (campo y } \\
\text { ruta de ripio). }\end{array}$ & $\begin{array}{l}\text { Tramos a } \\
\text { caballo y en } \\
\text { vehículos de } \\
\text { personas en } \\
\text { viaje }\end{array}$ & $\begin{array}{l}\text { Mensual o más } \\
\text { frecuente, estadías } \\
\text { que se limitan al } \\
\text { día }\end{array}$ & $\begin{array}{l}\text { Minifundio } \\
\text { ganadero en } \\
\text { producción (tierras } \\
\text { comunitarias) }\end{array}$ \\
\hline $\begin{array}{l}\text { Nuevo } \\
\text { productor de } \\
\text { aprox. } 45 \\
\text { años }\end{array}$ & $\begin{array}{l}\text { Principal } \\
\text { individual }\end{array}$ & $\begin{array}{l}\text { Paso de Indios } \\
\text { (1.264 hab.) } \\
\text { Trelew } \\
\text { (97.915 hab.) }\end{array}$ & $\begin{array}{l}50 \mathrm{~km} \mathrm{y} \\
400 \mathrm{~km} \text { (rutas } \\
\text { de ripio y } \\
\text { pavimentada) }\end{array}$ & $\begin{array}{l}\text { Vehículo } \\
\text { personal }\end{array}$ & $\begin{array}{l}\text { Semanal a Paso de } \\
\text { Indios y dos veces } \\
\text { al mes, estadías de } \\
\text { tres días en Trelew }\end{array}$ & $\begin{array}{l}\text { Establecimiento } \\
\text { pequeño con } \\
\text { producción agraria } \\
\text { diversificada }\end{array}$ \\
\hline $\begin{array}{l}\text { Productor } \\
\text { tradicional } \\
\text { de aprox. } 35 \\
\text { años }\end{array}$ & $\begin{array}{l}\text { Principal } \\
\text { individual }\end{array}$ & $\begin{array}{l}\text { Sarmiento } \\
\text { (10.858 hab.) }\end{array}$ & $\begin{array}{l}67 \mathrm{~km} \text { (caminos } \\
\text { y ruta de ripio) }\end{array}$ & $\begin{array}{l}\text { Vehículo } \\
\text { personal }\end{array}$ & $\begin{array}{l}\text { Semanal, estadías } \\
\text { que se limitan al } \\
\text { día }\end{array}$ & $\begin{array}{l}\text { Establecimiento } \\
\text { mediano en } \\
\text { producción }\end{array}$ \\
\hline $\begin{array}{l}\text { Productor } \\
\text { tradicional de } \\
62 \text { años }\end{array}$ & $\begin{array}{l}\text { Principal } \\
\text { individual }\end{array}$ & $\begin{array}{l}\text { Puerto San } \\
\text { Julián ( } 7.894 \\
\text { hab.) }\end{array}$ & $\begin{array}{l}70 \mathrm{~km} \text { (ruta de } \\
\text { ripio) }\end{array}$ & $\begin{array}{l}\text { Vehículo } \\
\text { personal }\end{array}$ & $\begin{array}{l}\text { Semanal, estadías } \\
\text { de un día }\end{array}$ & $\begin{array}{l}\text { Establecimiento } \\
\text { mediano en } \\
\text { producción }\end{array}$ \\
\hline $\begin{array}{l}\text { Productor } \\
\text { tradicional de } \\
68 \text { años }\end{array}$ & $\begin{array}{l}\text { Principal } \\
\text { familiar }\end{array}$ & $\begin{array}{l}\text { Puerto San } \\
\text { Julián }\end{array}$ & $\begin{array}{l}300 \mathrm{~km} \text { (rutas de } \\
\text { ripio). }\end{array}$ & $\begin{array}{l}\text { Camioneta } \\
\text { personal }\end{array}$ & $\begin{array}{l}\text { Mensual o menos } \\
\text { frecuente, estadías } \\
\text { de tres o cuatro } \\
\text { días }\end{array}$ & $\begin{array}{l}\text { Establecimiento } \\
\text { mediano en } \\
\text { producción }\end{array}$ \\
\hline $\begin{array}{l}\text { Nuevo } \\
\text { productor } \\
\text { de } 45 \text { años } \\
\text { (arriendo) }\end{array}$ & $\begin{array}{l}\text { Principal } \\
\text { individual }\end{array}$ & $\begin{array}{l}\text { Gobernador } \\
\text { Gregores } \\
\text { (4.497 hab.) }\end{array}$ & $\begin{array}{l}130 \mathrm{~km} \text { (caminos } \\
\text { y ruta de ripio) }\end{array}$ & $\begin{array}{l}\text { Vehículo } \\
\text { personal }\end{array}$ & $\begin{array}{l}\text { Mensual o más } \\
\text { frecuente, estadías } \\
\text { de dos días. }\end{array}$ & $\begin{array}{l}\text { Establecimiento } \\
\text { mediano en } \\
\text { producción }\end{array}$ \\
\hline
\end{tabular}

medicamentos y tratamientos no especializados con periodicidad trimestral en las visitas de los agentes del hospital rural. Los vínculos habituales en materia de acceso a los servicios de salud se producen con Alto Río Senguer o Río Mayo (equidistantes a 40 $\mathrm{km})$ y principalmente con Comodoro Rivadavia (según el recorrido a 308 o $410 \mathrm{~km}$ ) para el acceso a tratamientos de mayor complejidad o atención especializada. Las formas de movilidad incluyen todas las enunciadas y en ciertos casos el traslado en ambulancias. Los obstáculos señalados son las distancias y en consecuencia el tiempo que transcurre entre la necesidad efectiva de la prestación y la atención del paciente, los condicionantes físicos (como el estado de los caminos) y meteorológicos en inviernos rigurosos, obstáculos económicos por los costos, e incluso otros de índole cultural (Escudero \& Vazquez, 2014). 
ENTRE EL ÉXODO RURAL Y EL FORTALECIMIENTO DE LOS VÍNCULOS ESPACIALES

El declive de la estructura socio-territorial ovejera no sólo se reflejó en la reducción de los stocks provinciales de ovejas, sino también en el profundo despoblamiento del campo patagónico. El despoblamiento iniciado en la segunda mitad del siglo XX se aceleró en los dos últimos períodos inter-censales, con claras diferencias internas en lo referido a momentos e intensidades, tanto por las condiciones productivas, socieconómicas, culturales y políticas de los territorios, como por la ocurrencia de eventos (erupciones volcánicas y sequías prolongadas, entre otros) que precipitaron procesos de éxodo rural.

La variación poblacional del período inter-censal 1991-2001 indicó una disminución pronunciada en la cantidad de habitantes del campo santacruceño, con la excepción del $14 \%$ registrado en el departamento Lago Argentino, los porcentajes superaron ampliamente el $30 \%$ de la población rural de cada unidad departamental $e$ incluso el 50\% en departamentos de la Meseta Central.

El carácter precipitado del vaciamiento poblacional de los espacios rurales de la Meseta Central se debió a la erupción del volcán Hudson en agosto de 1991. La ocurrencia del fenómeno causó pérdidas de ganado por mortandad de entre el 30 y el $100 \%$ en los stocks de los establecimientos de la zona más afectada y generó intensas dificultades en la cría de ovejas, de allí el éxodo de trabajadores rurales y productores. Los productores de la zona contaron con cierto grado de capitalización y en la generalidad de los casos con una vivienda en una localidad 'cercana', situación que propició el éxodo de productores del tipo denominado arraigado hacia dichas localidades. Por lo tanto se coincide con Andrade (2014) pero con algunas salvedades, pues el autor considera al abandono como opción de aquellos productores que o tenían ingresos extra-prediales o con la venta de la explotación pudieron instalar un comercio o comprar viviendas para arrendar, omitiendo dos situaciones, por un lado, el éxodo de productores que no tenían ingresos adicionales y, por otro lado, el desfasaje temporal que existió entre los momentos de mayor despoblamiento y la etapa en la que se han concentrado las transacciones de tierras. Las dos situaciones se visualizan en el testimonio de un antiguo productor:

...la mano venía mal pero el volcán nos terminó, nosotros dejamos de producir en el año 92 (...), decían que era un fertilizante para los campos, tapó todas las aguadas, quemó los pastos y mató las ovejas, las ovejas flacas con mucho peso en la lana, caían y no se podían levantar, las aguadas se tapaban cada dos o tres días (...), después del volcán nos quedaron doscientos animales, los encerraba todos los días y el zorro me carneaba dos por día, en la zona todos estaban abandonando (...).Vendí las ovejas y me dediqué a hacer de todo un poco, a trabajar por día en una estancia acá de la zona de San Julián $y$ después a andar de mercachifle en los campos donde quedaba alguien; mi señora ayudaba limpiando el consultorio de un doctor y planchando en lo de una maestra, hasta que se me ocurrió abrir un quiosco acá en la casa para que ella no tenga que trabajar afuera y pudiera quedarse con los hijos que eran chicos (...). El volcán dijo déjense de joder, si no fuera por el volcán seguiría ahí y ¿qué futuro? (...) En el 2007 una empresa alquiló cerca de un año para sacar pórfido pero no funcionó (...), y antes de eso estuvieron los mineros explorando en otro campo y me alquilaron la casa un mes. Este año vendí a unos de Comodoro, me dolió vender, pero ahora me dio tranquilidad... (Antiguo productor de la zona de Gobernador Gregores - Bajo Caracoles, Santa Cruz, diciembre de 2011).

Por su parte, en el período inter-censal 2001-2010 el decrecimiento de la población rural dispersa superó el $40 \%$ en departamentos menos afectados en la década anterior, en Lago Argentino en Santa Cruz, en Paso de Indios y Languiñeo en Chubut y en San Antonio y Norquinco en Río Negro.

En las áreas de mesetas de Chubut y Río Negro el proceso de éxodo rural se habría 
intensificado en el marco de una coyuntura definida por sequías prolongadas y erupciones volcánicas (Chaiten en 2008 y Puyehue Cordón Caulle en 2011). Tal es así que las estadísticas publicadas por la Dirección de Ganadería de la Provincia de Chubut, con datos del 2014 y en relación a 2005, indican una disminución del $11 \%$ en la cantidad de productores de la Meseta (Dirección de Ganadería de la Provincia de Chubut, 2014). La diversidad de los porcentajes a escala de departamentos (entre 0 y 36\%) y los testimonios de los entrevistados, indican que el abandono ha sido menos pronunciado en sectores de la meseta con predominio de explotaciones minifundistas. Con respecto a las causas se puede conjeturar con las razones expresadas en la zona de Paso de Indios:

...el productor chico se aferra mucho, es muy aferrado a su campo, siempre tiene la esperanza de que el otro año le va a ir mejor, y eso le ayuda a seguir, a no abandonar lo poco que tiene... (Productor, enero de 2015).

...hay establecimientos abandonados y eso es un problema para los productores por los depredadores (...). Eso afecta más a los chicos que son los que siguen subsistiendo porque no les queda otra, los productores grandes tienen otras alternativas... (Técnica de la cooperativa De Vuelta Al Campo, enero de 2015).

Los espacios rurales de las comunidades indígenas también resultan afectados por los procesos de despoblamiento. Las formas heredadas (Santos 2000), desde puestos $y$ escuelas en condición de abandono, hasta ruinas y arboledas, lo indican en espacios con despoblamiento agravado como es el caso de Bajo La Cancha en oeste de Chubut. Los testimonios de los entrevistados se refieren al despoblamiento y al envejecimiento poblacional de las comunidades rurales ocasionado por el éxodo de los jóvenes:

...hay pobladores que bueno ya se están yendo de la tierra (...) quedan pocos jóvenes, algunos buscaron otros rumbos, otra calidad de vida para poder vivir, también jóvenes que se van a estudiar y el dia de mañana quieren hacer algo para la comunidad. Anecón tuvo muchísimos pobladores, cuando yo era chico querían hacer la escuela y no hallaban dónde, éramos más de 60 chicos (...), y muchos nos hemos ido, nosotros somos ocho hermanos y una de mis hermanas nomás está en el campo, cada tanto volvemos porque estamos a $85 \mathrm{~km}$... (Miembro de la comunidad Anecón Grande, Sur de Río Negro, enero de 2014).

...En la comunidad están todos lo que pasa que están los viejos nomás, alguno por ahí volvió, viven de la producción del campo, pero sobrevivís (...) hay varias familias acá, las casas habitadas son unas cuantas (...). Con Bajo La Cancha nos relacionábamos mucho porque antes habian fiestas que reunian y ahora se perdió eso también, no sé si queda alguno ahí... (Miembro de la comunidad Tramaleo, Oeste de Chubut, octubre de 2015).

...La mayoría somos hombres solos, los familiares se han desparramado por todos lados, Río Mayo o Comodoro, algunos para Las Heras, la juventud se ha ido casi toda a las empresas (empresas del sector petrolero). Pero hay gente joven igual, chicos que han salido de la escuela y los han traído los padres, acá tenemos nomás a__ que ha traído a los chicos y ya andan trabajando en las estancias de por día o mensual... (Miembro de la comunidad El Chalía, SO de Chubut, julio de 2015).

En sintesis, actualmente se observa un decrecimiento muy marcado de las lógicas campo-localidad, y el predominio de dos situaciones entre las explotaciones de tipo familiar: 1) la continuidad del productor (o del productor y su esposa) ante el éxodo de los otros miembros del grupo familiar, y; 2) el éxodo de todo el núcleo familiar. Dos situaciones que pueden ser niveles de un mismo proceso de éxodo rural familiar, al respecto son ilustrativos los siguientes testimonios: 
...era de acá el hombre, pero le pasó lo mismo que a todos, llegó cierto tiempo que se quedó sin ovejas y tenía los chicos en edad escolar, entonces se querian ir al pueblo (...), el tema es que en familia no podés estar en el campo, llega cierto tiempo de tu familia, que te tenés que ir, es un problema eh, hay mucha gente que no aguanta, en la mayoría de los casos la ida del campo es esa, los chicos empiezan a estudiar y se van todos... (Productor de la zona del paraje Cerro Cóndor, Chubut, enero de 2015).

...una vez que se vino la señora con los chicos al pueblo, el tipo no aguantó más de un año o dos y se vino, y ahí es donde se fue despoblando, no tenés gente, el mayor problema no es la ceniza o la sequía, el mayor problema es que no tenés gente que trabaje en el campo, que esté en el campo, que esté atrás de la oveja, que persiga al zorro, que arregle un alambre... (Extensionista del INTA en Paso de Indios, enero de 2015).

Mi esposa trabaja en una escuela acá en Jacobacci y yo en la cooperativa ganadera (...). Mis hijos iban a la escuela en Comallo y paraban en la casa de una hermana (...) Pero la mano venía mal, ocho años de sequía, y mi mujer consiguió trabajo acá en la escuela y nos vinimos (...). Hasta el año pasado estuve mucho en el campo, meses enteros, después por problemas de salud tuve que aflojar. Había quedado una persona cuidando las ovejas, hasta que no fue negocio para ninguno de los dos (...), me quedaban setenta que están en lo de un vecino (...) Hay muchos productores que siguen en el campo, la mayoría son gente grande y muchos tienen jubilación... (Antiguo productor de la zona del paraje
Futa Ruin, Sur de Río Negro, enero de 2014).

El éxodo de todo el grupo familiar generalmente implica el abandono de la producción, máxime en establecimientos donde las distancias excluyen su sostenimiento desde la pluriactividad del actor, ya que los costos obstaculizan la contratación de un empleado en estas escalas de producción. Bendini y Steimbreger (2013) observan en el sur de Río Negro casos de pluriactividad que se sostienen en nuevas formas de movilidad localidadcampo o campo-campo. Las autoras sostienen que esta nueva movilidad espacial laboral es parte de los cambios adaptativos y las estrategias de resistencia campesina, aunque advierten acerca de otras miradas que la relacionan con procesos de descomposición social y descampesinización (2013, pp. 35-37) ${ }^{3}$.

En ese contexto de éxodo rural se conforma un estrato numeroso de tenedores absentistas con características socio-económicas y espaciales distintas a las del absentista tradicional. Entre estos nuevos propietarios absentistas la movilidad está condicionada por la rutina en otros espacios y se produce de manera regular $\mathrm{u}$ ocasional como sucede entre antiguos productores (envejecidos y/o descapitalizados) o herederos con campos en lugares distantes de su residencia, deshabitados y muchas veces despojados de las instalaciones.

Nosotros vamos más o menos cada 15 días y nos quedamos 2, cuando vamos regamos, arreglamos los alambres y esas cosas, lo mantenemos. Costó irse del campo y ahora te cuesta volver... (Antiguo productor de la zona del paraje Futa Ruin, Sur de Río Negro, enero de 2014).

Yo soy de ahí, pero vivo acá, trabajo acá pero soy de ahí, incluso soy descendiente de cacique (...) y pude recuperar una parcela de la familia (...). Es propiedad individual pero también tenemos el título
3 En la revisión de antecedentes que realiza Comerci (2013) expone que en los espacios extra-pampeanos se observa: el desarrollo de distintas prácticas de adaptación/resistencia, que expresan cierta flexibilidad del campesinado ante los procesos de cambio a los que se ven sometidos y cierto fortalecimiento de los lazos sociales y prácticas tradicionales (Comerci, 2013, p. 4). 
de la reserva o sea el de la comunidad, no se puede vender pero por lo menos queda, el problema por ahi son nuestros hijos que nos les gusta el campo (...). Por ahí los fines de semana me pego una vuelta, a visitar porque son familia y de paso es bueno porque a veces encontrás gente que necesita algo... (Miembro de la comunidad Tramaleo, Chubut, septiembre de 2013).

...Como está eso a qué vas a ir, a llorar, nosotros no vamos desde que mis padres se fueron, por ahi mis hermanos van cada tanto, una vez al año... (Propietaria de establecimiento en la zona de Bajo Caracoles, Santa Cruz, julio de 2015).

Paralelamente a esos cambios, tanto el desarrollo del asociativismo en sus diversas modalidades organizativas como el fortalecimiento de los vínculos al interior de las comunidades indígenas y entre ellas, complejizan las lógicas espaciales de los actores.

El asociativismo se desarrolla con iniciativas locales y políticas públicas dirigidas a los pequeños productores. Los objetivos de las asociaciones y las cooperativas son diversos, la reconversión o diversificación productiva en el caso de aquellas conformadas en el marco del Programa Federal de Reconversión Productiva para la Pequeña y Mediana Empresa Agropecuaria (Cambio Rural) u otros más integrales. Ejemplo del primero tipo es el caso de un grupo de ganaderos del Valle Medio del río Chubut que en la segunda mitad de los años 90 se vincula con eje en la producción de alfalfa y conforma la Asociación VAMERCH, una entidad que nuclea unos veinte productores dispersos a lo largo de $350 \mathrm{~km}$. Y entre las formas organizativas con objetivos más amplios se destaca por el contexto de surgimiento la Cooperativa De Vuelta Al Campo, una cooperativa integrada por más de cincuenta productores de lana y/o de pelo mohair, que se crea a partir de iniciativas municipales y acciones de organismos estatales del sector agropecuario, con la intención de revertir la dinámica demográfica negativa, es decir descensos en la población rural dispersa que en el último período inter-censal (2001-2010) alcanzaron el $50 \%$ en el departamento Paso de Indios. Estas formas organizativas que Carricart (2012) asocia a la idea de sistema territorial, buscan profundizar los vínculos entre actores a partir de reuniones, capacitaciones, ferias u otros eventos que convocan tanto en el campo como en las localidades.

Hacemos unas 6 o 7 reuniones por año, generalmente en el campo, porque también hacemos capacitaciones. Hay productores que están muy comprometidos, orgullosos de lo que lograron (...) La fortaleza es que hay un grupo muy unido, que se habla de todo, se discute todo en las reuniones, son muchos años... (Asesor técnico y productor de la asociación VAMERCH, enero de 2015).

El proyecto de Vuelta Al Campo surgió de toda la gente que se fue quedando sin ovejas y se fue al pueblo, se fue a Paso de Indios, pero la misma política los fue llevando al pueblo, porque les fue dando casa, asistencialismo, entonces el que más que menos si en el campo no recibís nada $y$ en el pueblo recibís (...); y bueno hay mucha gente de esa que se fue al pueblo, que si analizas los del proyecto quedaron cuatro o cinco nomás en el campo, porque después vino la sequía, la ceniza y se han quedado sin ovejas de vuelta, entonces los que están aguantando son los que siempre estuvieron en el campo... (Presidente y productor de la cooperativa De Vuelta $\mathrm{Al}$ Campo, enero de 2015).

En las comunidades (y entre las mismas) el fortalecimiento de los vínculos también se produce con el proceso de visibilización de la cuestión indígena. Este hecho se evidencia por ejemplo en acciones que se generan en el medio rural con poblaciones campesinas y actores con residencia en pueblos y ciudades. En relación a esto Rodríguez señala que, con el reemplazo de reservas por comunidades, la localización en sitios fijos, devino flujo continuo entre las zonas rurales y urbanas (2008, p. 2). Estas movilidades también se observan en comunidades no conformadas con base territorial comunitaria (reservas), así lo indica el caso de la comunidad Newen Nuque Mapu, una 
comunidad que nuclea a más de cuarenta familias de parajes próximos a la cuenca del arroyo Comallo. La comunidad Newen Nuque Mapu se constituye en el contexto de emergencia generado por la erupción del volcán Puyehue (2011), formalizando un proceso de comunalización que se inició en los años cuarenta y se fortaleció en contextos de crisis y emergencias, con experiencias organizativas y vínculos asociados a reclamos colectivos (Cañuqueo et al. 2015). En síntesis, germinan otras lógicas mediante acciones ligadas a nuevas formas organizativas, a reafirmaciones identitarias, defensas y reivindicaciones territoriales. El recuadro 1 presenta un relato que ejemplifica las nuevas movilidades.

Recuadro 1. Reivindicaciones territoriales, actores y movilidad. Asamblea en el paraje Cañadón Chileno.

El encuentro se realizó con motivo del conflicto que sostiene una familia de productores de la comunidad mapuche Newen Nuque Mapu con actores de la estancia Los Amigos (de propietario absentista, localmente representados en la figura del administrador); conflicto que se origina con el cambio dominial y tiene su génesis en las consecuencias del reemplazo de alambrados y la anulación de una cancela, como la imposibilidad de retirar el ganado que ingresó a la estancia y de utilizar un cuadro que en su condición de abandono durante más de tres décadas fue utilizado por el criancero para el pastaje de sus animales. El conflicto se suma al que sostiene con la estancia otra familia con miembros en la reunión.

$\mathrm{Al}$ encuentro concurrieron las familias de la comunidad implicadas en el conflicto, el Lonko y otros miembros de la misma, así como de otras comunidades y demás actores que llevan adelante el reclamo: consejeros del Consejo de Desarrollo de las Comunidades Indígenas (CoDeCI), representantes del Parlamento Mapuche, miembros de la Pastoral Indígena y representantes tanto de la Cooperativa Ganadera Indígena como de la Federación de Cooperativas. En definitiva, la asamblea nucleó pobladores rurales y actores urbanos de Ing. Jacobacci y San Carlos de Bariloche.

Los desplazamientos con destino a la reunión se realizaron especialmente en camionetas sobre caminos de ripio o consolidados en condiciones de regulares a malas y excepcionalmente a caballo. Los actores que disponían de vehículo, en su mayoría en viaje desde Ingeniero Jacobacci o desde algún establecimiento de la zona, colaboraron en el traslado de otros partícipes de la reunión, actores que en casos aguardaban en la localidad de Comallo (residentes o en viaje desde Bariloche) o en puestos camino al sitio.

Fuente: registros del autor en rol de observador participante, enero de 2014.

\section{LÓGICAS ESPACIALES DE UN PRODUCTOR SANTACRUCEÑO ENTRE 1955 Y 1991}

La lectura realizada en base a la revisión bibliográfica y las tareas de campo, se complementa con una lectura más profunda, un análisis micro realizado en base a los registros diarios de la familia Moyes y desde el espacio vivido de un productor de lana de la Meseta Central de Santa Cruz . Un productor arraigado abocado a la cría extensiva de ovejas en una explotación con las siguientes características:

- una cantidad promedio de 2.600 ovinos y stocks que desde el año 1983 tuvieron una disminución muy marcada,

- un manejo año redondo (no rotativo) en

las 10.000 has de campo de la estancia,

- fuerza de trabajo exclusivamente familiar

o familiar y extra-familiar (un trabajador permanente).

La fuente no sólo posibilita alcanzar un mayor nivel de detalle en el análisis de las lógicas espaciales del productor, sino también las rupturas y continuidades existentes a lo largo de la etapa de registro (1955-1991), pues la amplitud del período brinda la posibilidad de identificar cambios en las prácticas espaciales de los actores rurales, que pueden ser analizados en función de distintos contextos.

Por lo tanto, en primer lugar se presenta el espacio vivencial definido por la movilidad extra-predial del productor, movilidad que vinculaba al establecimiento con otros espacios de la Patagonia ovejera, otras estancias, puestos, boliches, destacamentos policiales, escuelas hogar, cruces de caminos, parajes, pueblos y pequeñas ciudades (Fig. 7). Y posteriormente, los cambios en la territorialidad del productor y los factores que habrían motivado dichos cambios.

El espacio de la cotidianeidad del productor era el rural disperso en un radio aproximado de $30 \mathrm{~km}$ desde el establecimiento. Este espacio contenía elevadas sinergias tanto en lo relativo a la producción agropecuaria como en los aspectos domésticos de la vida en el campo, pues en él había establecido relaciones de vecindad y cooperación, frecuentes y sostenidas.

Los desplazamientos a otras estancias, 


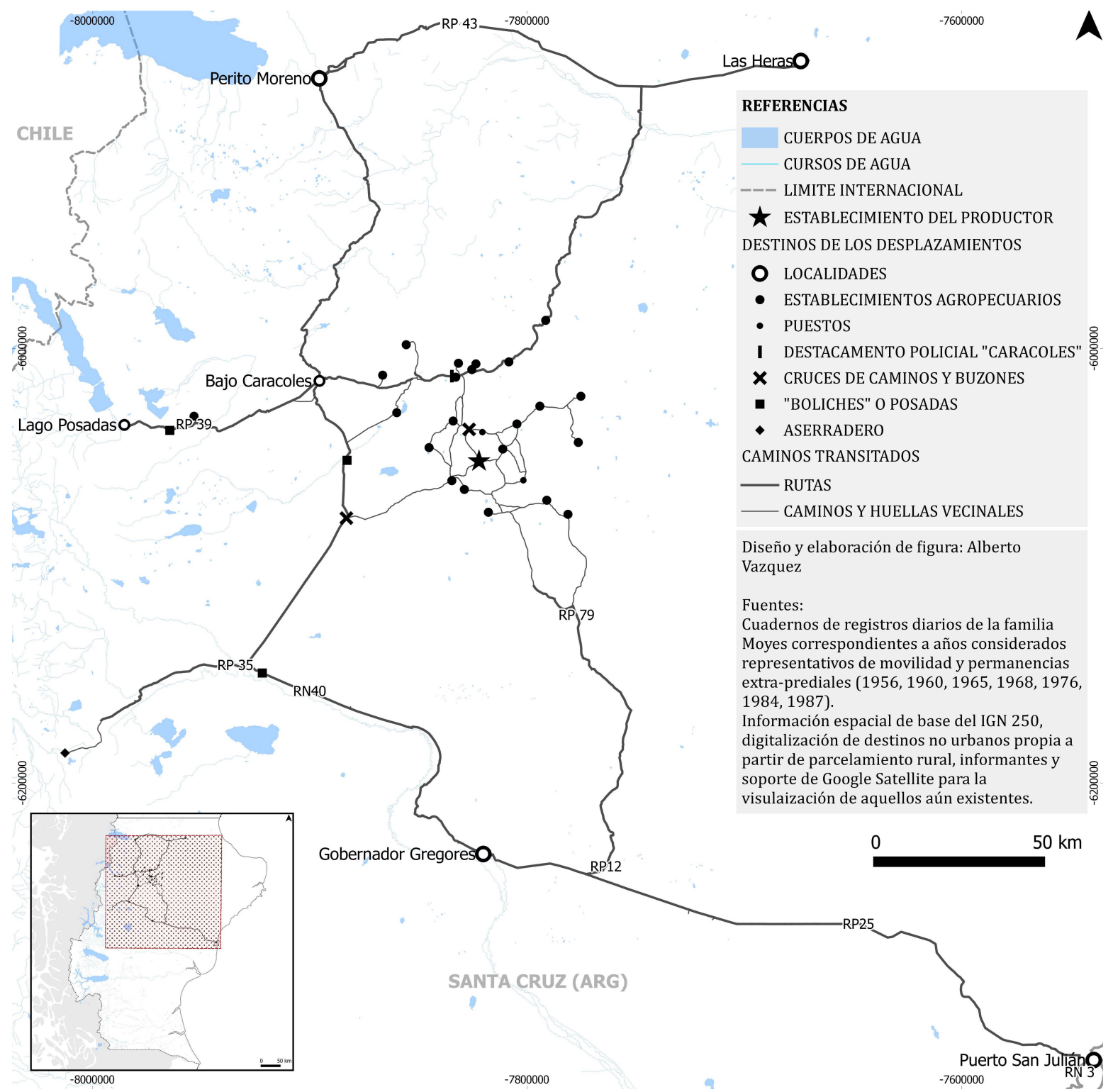

Fig. 7. Destinos de los desplazamientos en años representativos de las lógicas espaciales de un productor de la Meseta Central de Santa Cruz en el intervalo 1955-1991. Fuente: elaboración propia.

a caballo o en el vehículo a automotor, eran frecuentes con motivo de colaborar en el desarrollo de prácticas ganaderas o en tareas como el arranque y acarreo de mata negra (leña), retirar animales propios de campos linderos, contactar la comparsa de esquila (máquina de esquila y esquiladores) y el personal necesario para los trabajos, trasladar personas y objetos, y visitar conocidos o familiares, entre otros. Los desplazamientos eran constantes pero se incrementaban entre los meses de diciembre y febrero, cuando se concentraban en la zona prácticas ganaderas de cierta envergadura (esquila y señalada). Las estadías en esas estancias generalmente no superaban el día, sólo lo hacían en casos excepcionales o cuando el productor se trasladaba junto a otros miembros del grupo familiar en algunos momentos de esparcimiento.

La movilidad en el medio rural también se producía en función de las diferentes estrategias desarrolladas por los pobladores 
para los traslados entre el campo y los pueblos o parajes. En ese sentido, eran habituales los desplazamientos del productor a otras estancias con el propósito de transportar personas y objetos, de realizar encargues cuando algún vecino estuviese por viajar al pueblo o de retirarlos cuando hubiese regresado. Y también los desplazamientos a los cruces, a veces, al cruce de huellas vecinales ubicado a $12 \mathrm{~km}$ del casco, lugar de encuentro acordado con los vecinos en viaje que colaboraban con el transporte de personas $\mathrm{u}$ objetos $\mathrm{y}$, otras veces, al cruce con la $\mathrm{RN} \mathrm{40}$, ruta ubicada a $50 \mathrm{~km}$ del casco por la que transitaba el medio de transporte colectivo que realizaba el recorrido Puerto San JuliánGobernador Gregores-Bajo Caracoles. En esos cruces de caminos se habían colocado buzones de correspondencia, la comunicación a través de cartas fue de suma importancia hasta la llegada de los transmisores de frecuencia modulada y la comunicación de radio aficionados, pues el telégrafo con bajadas tanto en el paraje Bajo Caracoles como en el destacamento policial Caracoles era utilizado por el productor sólo en ocasiones excepcionales ${ }^{4}$.

Claramente, las relaciones de vecindad y cooperación se habían potenciado por el aislamiento físico con respecto a las localidades. Las distancias a las localidades con primacía en las lógicas espaciales del productor eran muy significativas, las distancias en el espacio absoluto de $420 \mathrm{~km}$ o $350 \mathrm{~km}$ a Puerto San Julián y de $220 \mathrm{~km}$ a las Heras, y más aún las distancias en el espacio relativo, es decir aquellas resultantes de la conjunción de la distancia física con las condiciones técnicas de movilidad, considerando los vehículos disponibles en las primeras décadas y el estado de las huellas heredadas de la época del tránsito de las carretas ${ }^{5}$.

4 Los buzones en el cruce de la RN 40 aún hoy y a pesar de la pérdida de funcionalidad, dan el nombre al sitio: cruce de los cinco buzones.

5 En relación a las características de movilidad en la zona son ilustrativos los relatos de Ella Hoffman Brunswig con respecto a su viaje desde Puerto San Julián a la estancia del Lago Ghío en 1923: ...El camino, por cierto, no es lo que en Alemania entendemos por tal: lo marcan las huellas de las enormes carretas que transportan la lana desde las estancias al puerto. A veces las huellas se ven nitidas y parejas, a veces son tan profundas que una no se explica cómo el pequeño auto brinca y serpentea por
La que hoy es la ruta 12, hasta el 60 y pico no existía, era vecinal del tiempo de las chatas y se andaba en primera o en segunda con unos camiones chicos sin duales que la habian marcado un poco, recién en el 57 se hizo un consorcio para pagar entre los pobladores y un tal Felgueroso con un tractor tirando una máquina, limpió un poco casi por el mismo camino que era la huella de los carros, en algunas partes un poco más derecho, y después en el 66 o por ahi, hicieron la ruta, desde la 25 hasta el hotel Dos Manantiales, creo que fue un decreto nacional, y después prosiguió para Pico Truncado... (Antiguo productor de la zona, enero de 2016).

Tal es así que la movilidad hacia las localidades era muy limitada, en los primeros años no viajaba más de tres veces a la localidad de Puerto San Julián y el recorrido era realizado por tramos con pernocte en otras estancias, en Cañadón León (actualmente Gobernador Gregores) o en esos boliches del camino que fueron necesidad y tradición en estos espacios con paradas muchas veces obligadas en función de las distancias ${ }^{6}$.

Por otra parte, más allá de las distancias y las condiciones técnicas de la época, la rigurosidad de los inviernos profundizaba el aislamiento. Los desplazamientos a las localidades eran mayores en la etapa comprendida entre el final de los trabajos (esquila y señalada) en enero o febrero y el inicio del invierno. Entre los registros invernales considerados, los correspondientes a los años 84 y 87 son los más ilustrativos. En el año 84 no se realizaron desplazamientos durante la estación, las precipitaciones en forma de nieve superaron los $100 \mathrm{~cm}$ en la etapa mayo-septiembre (con una

ellas (...). Estos tres días en auto han sido hasta ahora la culminación de nuestro viaje (...). jSólo en el mar he visto tanta grandeza, vastedad y fuerza! (Brunswig de Bamberg, 2012, pp. 37-41)

6 La importancia de los boliches del camino en el funcionamiento de los espacios ovejeros se ha visualizado en el análisis geo-histórico que Bondel, Novara y Ñancufil (2005) realizaron sobre la base de los registros históricos de los huespedes del boliche Los Tamariscos (centro-sur de Chubut). Y también se ha representado en la literatura regional, por ejemplo en el cuento El boliche de la Güeya (Abeijón, 2008, pp. 15-23). 
concentración del $50 \%$ en el primer mes) y fueron acompañadas de temperaturas extremas de hasta $-23^{\circ} \mathrm{C}$ (mediciones familiares a $47^{\circ} 40^{\prime}$ de latitud Sur y a $670 \mathrm{msnm})$. Si bien en el año 87 tampoco se registraron desplazamientos durante el invierno, la residencia fue urbana durante la estación.

La movilidad a las localidades era multipropósito, por lo que las estadías solían superar la semana. Las estadías eran funcionales a la atención de obligaciones bancarias y administrativas, el acceso a servicios de salud, la compra de insumos para la producción y de bienes de consumo para el abastecimiento anual en la explotación, la reparación de objetos (principalmente el vehículo) y sólo ocasionalmente, cuando no era comercializada con compradores ambulantes, la venta de la lana y/o las pieles. Por otro lado, eran importantes las motivaciones afectivas de la estadía, pues cuando se establece la residencia permanente de miembros de la unidad doméstica en la localidad de Las Heras se produjo un marcado incremento tanto en la frecuencia de los desplazamientos como en la cantidad de días de las estadías en la localidad (Fig. 8).

Los desplazamientos a las otras localidades del área eran menos frecuentes y se producían con propósitos específicos. Los desplazamientos al paraje Bajo Caracoles, uno o dos al año, se producían por temas administrativos, principalmente la tramitación en el juzgado de paz de las guías para el traslado de lana, cueros o ganado en pi $e^{7}$. Por su parte, los desplazamientos a Lago Posadas, Gobernador Gregores y Las Heras en años previos a su lugar de primacía en las lógica campo-localidad del productor (ver en la Fig. 8 las vistas correspondiente a los años 1960 y 1965), se debían principalmente a la escolarización de los hijos, por lo tanto se producía en los momentos de inicio, receso y final del ciclo lectivo. El ciclo lectivo comprendía de septiembre a mayo e implicaba la residencia de los hijos en el lugar, ya sea en escuelas con internado como la escuela hogar de Lago Posadas o en casas particulares de familiares

7 Un paraje compuesto por un hotel (almacén de ramos generales), la comisaría, el juzgado de paz y algunas viviendas.

8 La escuela fundada en 1936 en uno de los edificios de la estancia Lago Posadas, fue la segunda institución educativa nacional que se ajustó a la categoría Escuela Hogar en el y $\operatorname{conocidos}^{8}$. Por otra parte, los viajes a Perito Moreno eran excepcionales y generalmente se hacían para comprar pasto -fardos de alfalfa- en las chacras de la localidad (Fig. 8).

...de ahí cerca de San Agustín ya éramos como ocho que papá llevaba a la escuela de Lago Posadas, nos llevaba a nosotros, también chicos de La Flora, los hermanos de Mónica y después pasábamos a El Unco y a Río Blanco a buscar otros chicos. Papá ponía una lona en la caja del camión y nos llevaba. En El Unco solíamos almorzar y algunas veces papá alojaba ahí cuando volvía a San Agustín... (Miembro del grupo familiar, enero de 2016).

Más allá de la caracterización general de las lógicas espaciales del productor, interesa cerrar el análisis profundizando en los cambios relacionados con el avance de la técnica y la progresiva reducción de las distancias en el espacio relativo, con los procesos de reorganización del espacio santacruceño, la expansión de la actividad hidrocarburifera en la cuenca del golfo San Jorge y el dinamismo de Las Heras a partir de los años sesenta y con diversas situaciones familiares $y$ productivas.

Partiendo de una etapa con vínculos consolidados en el medio rural y una movilidad campo-localidad muy limitada, de menos de tres viajes por año con ausencias en el establecimiento que oscilaban entre siete y dieciséis días, se identifican tres grandes cambios en el comportamiento espacial del productor:

- incremento de la movilidad campolocalidad y dispersión del espacio relacional: inicialmente se incrementaron los viajes a Puerto San Julián y con posterioridad se multiplicaron los destinos de los desplazamientos (vista del año 1960 en la Fig. 8).

- disminución de la movilidad extra-predial:

marco de la ley de Protección a los niños en edad escolar (ley 12.558). Esa ley creó la Comisión Nacional de Ayuda Escolar que tenía como prioridad la asistencia médicoescolar en las provincias del Norte y en los territorios nacionales (Billorou, 2011). 


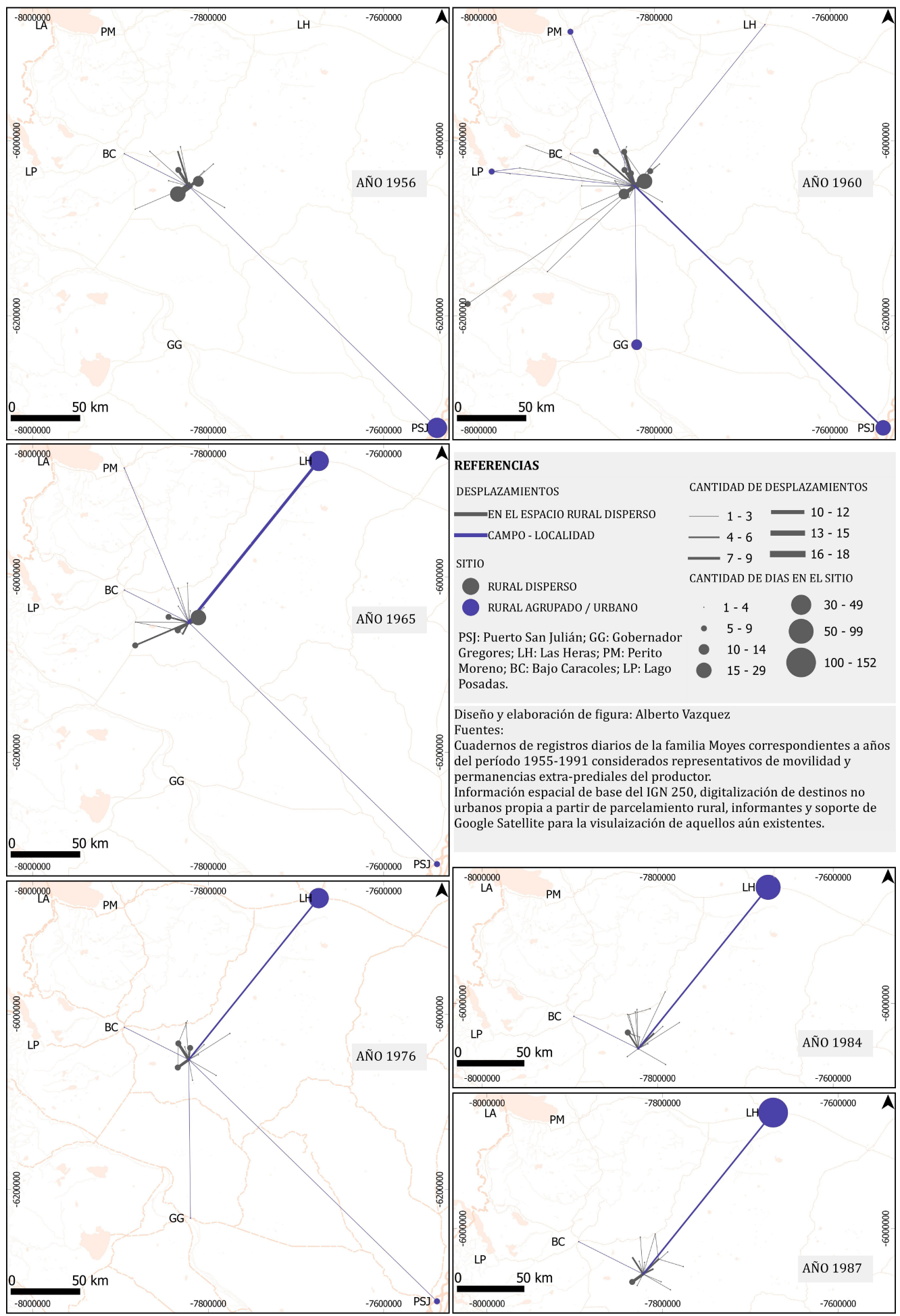

Fig. 8. Modelos representativos de movilidad y permanencias extra-prediales de un productor de la Meseta Central de Santa Cruz en la segunda mitad del siglo XX. Nótese en las últimas figuras tanto la compresión del espacio relacional como el incremento en las estadías urbanas. Fuente: elaboración propia. 
disminuyó de manera significativa la movilidad del productor, en especial la relacionada con prácticas ganaderas en otras explotaciones (vista del año 1976 en la Fig. 8).

- compresión del espacio relacional e incremento de las estadías urbanas: se achicó el espacio relacional y se incrementaron las estadías en Las Heras (vistas de los años 1984 y 1987 en la Fig. 8), alterando incluso la dinámica estacional con residencias extendidas durante el invierno (Figs. 9 y 10 ).

Mientas los primeros cambios se deben a situaciones familiares, el primero a la escolarización de los hijos y el segundo a la redistribución de las tareas que se produce cuando concluye la educación formal de los hijos, el último requiere de la consideración de diversos aspectos para poder ser explicado.

La compresión del espacio relacional del

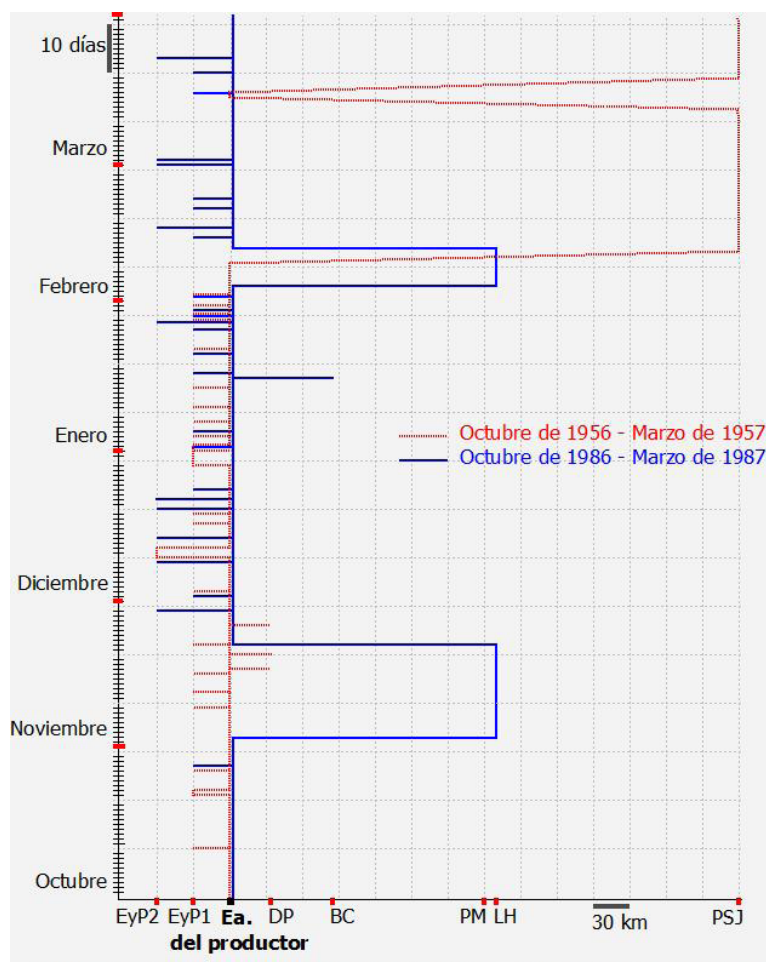

EyP1: estancias y puestos, en distancias $\leq$ a $30 \mathrm{~km}$; EyP2: estancias y puestos, en distancias $\leq$ a 60 km; BC: Bajo Caracoles; PM: Perito Moreno; LH: Las Heras; PS]: Puerto San Julián. productor y el incremento de sus estadías urbanas son indicadores de un proceso de éxodo rural familiar que culmina en el año 1991 con el abandono del establecimiento. El éxodo puede explicarse con los elementos que brinda la propia fuente, los datos productivos dan cuenta de los resultados negativos de la actividad y la información familiar del éxodo de los hijos y del envejecimiento de los productores. Por un lado, los registros indican que el descenso en el stock de ganado fue sostenido desde el año 83, pues en el contexto de un ciclo seco dividido por las grandes nevadas del año 84, las cuantiosas pérdidas por mortandad no fueron acompañadas de buenas pariciones, los porcentajes de señalada no superaron el $45 \%$ desde el año 81 y fueron extremadamente bajos a partir del 83: el 19\% en 1983 , el $2 \%$ en 1984 , el $35 \%$ en 1985 y el $27 \%$ en 1986. Por otro lado, para el año 86 los hijos habían constituido su unidad familiar y no residían en el establecimiento, los hijos varones residían en

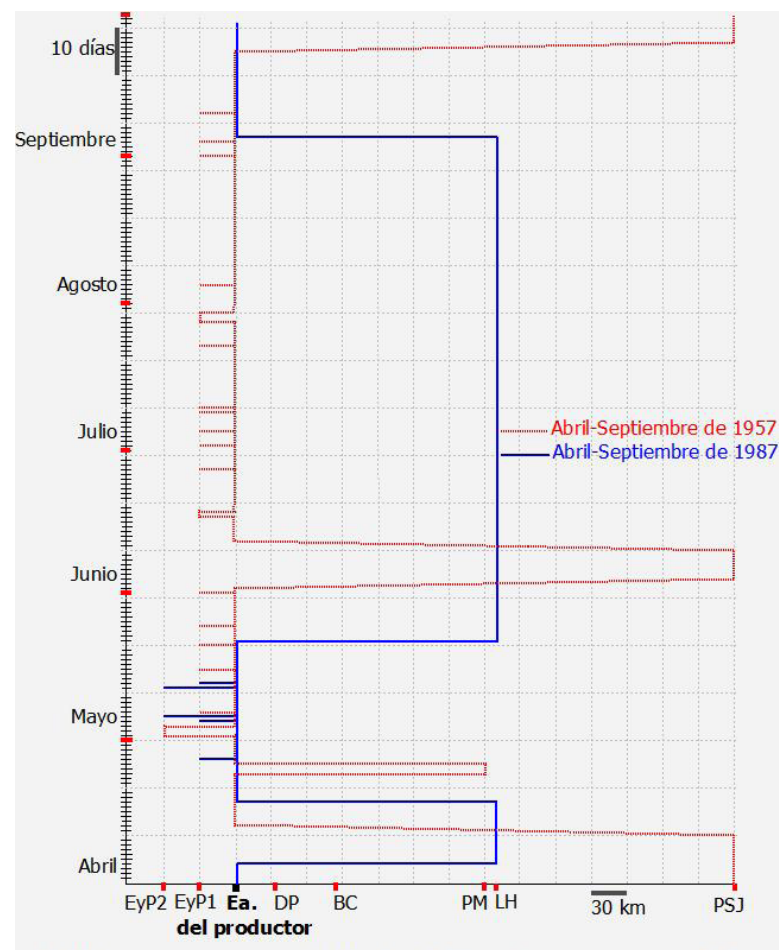

EyP1: estancias y puestos, en distancias $\leq$ a $30 \mathrm{~km}$; EyP2: estancias y puestos, en distancias $\leq$ a 60 km; BC: Bajo Caracoles; PM: Perito Moreno; LH: Las Heras; PS]: Puerto San Julián.

Figs. 9 y 10. Diorama espacio-temporal que representa comportamientos espaciales de un productor de la Meseta Central de Santa Cruz en los extremos de una etapa de registro de más de 30 años de la segunda mitad del siglo XX. Nótese el cambio en el comportamiento espacial durante el invierno. Fuente: elaboración propia en base a los registros diarios de la familia Moyes. 
Las Heras con empleos vinculados a la actividad hidrocarburífera y la hija alternaba entre Puerto San Julián y otra estancia de la zona.

\section{CONCLUSIONES}

En un complejo mundo rural patagónico donde los vínculos espaciales y sus escalas son indicadores de desigualdades socio-económicas y diferencias culturales, las lógicas consideradas distinguen a un tipo de productor que construye sus territorialidades en áreas definidas desde la movilidad a escala local. Movilidad motivada por las relaciones de vecindad y cooperación, los temas afectivos, el acceso a bienes y servicios, el trabajo extra-predial, etc.

El análisis geo-histórico del comportamiento espacial del productor santacruceño entre 1955 y 1991 presentó con nivel de detalle territorialidades y territorios congruentes con la funcionalidad ovejera. En territorios que hoy muestran sólo en formas heredadas la pre-existencia de lógicas espaciales campesinas, la fuente histórica exhibe áreas de vivencias con vínculos socio-territoriales sostenidos en un radio de unos $30 \mathrm{~km}$, es decir modos de habitar el campo patagónico que rompen con la idea del campo como un espacio netamente productivo.

La fuente propició una lectura bidireccional del declive ganadero y el éxodo rural, generando argumentos para complejizar la explicación de estos procesos muchas veces reducidos a una progresiva disminución de la receptividad ganadera de los suelos. La información recuperada de la fuente ha mostrado las limitaciones de esa interpretación dominante en los estudios regionales. En primer lugar, la información productiva indica que el descenso en los stock de ganado no fue progresivo, pues se precipitó desde el año 83 en el marco de un ciclo seco que reunió los dos eventos meteorológicos más destacados de la etapa de registro: la intensa sequía del año 1983 (los 84 mm registrados no tiene parangón a lo largo de la etapa de registro) y las intensas nevadas del año 1984. En segundo lugar, la información familiar da cuenta del éxodo de los hijos y del incremento de las estadías de los productores en la localidad, situaciones que no sólo se explican por los factores de empuje, sino también por los factores de atracción de la localidad, las posibilidades laborales en el sector hidrocarburífero, el acceso a los servicios, la cercanía a los afectos, etc. Más aún si se considera la conformación de las unidades familiares de los hijos y el envejecimiento del productor y su esposa.

Del análisis macro surge que el despoblamiento rural impacta en toda la estructura regional. En el campo disminuyen o desaparecen relaciones de vecindad y cooperación, se pierden conocimientos locales y posibilidades de cambio generacional, y se acrecientan las dificultades en la cría extensiva de ganado menor por la pérdida de contigüidad espacial de la producción (Vazquez \& Novara, 2012). Por otra parte, también se debilita la función de las localidades y el proceso de redistribución poblacional depara para las mismas un rol de centralidad en los flujos poblacionales o directamente la pérdida poblacional por el éxodo hacia asentamientos de mayor jerarquía.

Finalmente, se entiende que los reacomodamientos del período demandan lecturas que atiendan a la complejidad socioterritorial, evitando visiones estáticas en relación al funcionamiento de los espacios. En ese sentido, la consideración de las lógicas espaciales de los actores permite el análisis territorial desde las relacionales que operan en diferentes escalas. Como se ha mostrado, en la escala local se debilitan las lógicas campesinas tradicionales y se desarrollan otras relacionadas al abandono, a la pluriactividad, a nuevas formas organizativas, a reafirmaciones identitarias y a defensas y reivindicaciones territoriales. Y por otro lado, un grupo cada vez más numeroso de actores urbanos, heterogéneo en intencionalidades, despliega lógicas en diversas escalas (local, regional, nacional y transnacional). El análisis de esas lógicas asociadas a una condición que siguiendo aportes de Haesbaert (2013) se ha denominado multiterritorialidad dominial (Vazquez 2014), es la dirección pretendida en próximas etapas de la investigación.

\section{AGRADECIMIENTOS}

A la familia Moyes por confiarme los registros diarios y la predisposición ante las consultas.

A quienes fueron entrevistados o colaboraron con el desarrollo de las tareas de campo.

A Santiago Bondel por la revisión del artículo 
y las sugerencias.

A Alejandro Aguado por el dibujo que ilustra el contenido.

\section{BIBLIOGRAFÍA}

Abeijón, A. (2008). Caminos y rastrilladas borrosas. Memorias de un carrero patagónico. Comodoro Rivadavia, Argentina: Imprenta Gráfica de Armando E. Andrade.

Andrade, L. (2014). La mirada sociológica sobre la desertificación en la meseta central santacruceña (Patagonia austral, Argentina). Zonas Áridas, 15(2), 402-417.

Benedetti, A., \& Salizzi, E. (2011). Llegar, pasar, regresar a la frontera. Aproximación al sistema de movilidad argentino-boliviano. Transporte y Territorio, 4, 148179.

Bendini, M., \& Steimbreger, N. (2011). Ocupaciones y movilidades en pueblos rurales de la Patagonia. Una mirada desde lo agrario. Mundo Agrario, 12(23), 1-26.

Bendini, M., \& Steimbreger, N. (2013). Territorialidad campesina en el sur de Argentina. Cambios productivos y laborales como formas de resistencia. Eutopía, 4, 2544.

Billarou, M. J. (2011). La labor de la Comisión de Ayuda Escolar (1938-1943): encarar la acción en su verdadero concepto de imperativo social. En Cosse I., Llobet, V., Villalta, C., Zapiola, M. C. (Ed.), Infancias: políticas y saberes en Argentina y Brasil. Siglos XIX y XX (207234). Buenos Aires, Argentina: Teseo.

Bondel, C. S., Novara, M., \& Ñancufil, A. (2005). Desplazamientos en la Patagonia central a mediados del siglo XX. Etapa inicial de un rescate geo-histórico regional fortalecido con el uso de SIG. En VI Congreso de Historia Social y Politica de la Patagonia Argentino-Chilena, Trevelín.

Bondel, C. S., \& Vazquez, A. D. (2013). Transformaciones territoriales y ruralidad. Investigación proyectada en ámbitos patagónicos esteparios. En IV Congreso Nacional de Geografía de Universidades Públicas, Mendoza.

Bondel, C. S. (2015). Ausentismo y organización del espacio. Aportes preliminares en casos patagónicos. Revista de Informes Científicos Técnicos ICT-UNPA, 7(1), 3038.

Brunswig de Bamberg, M. (2012). Allá en la Patagonia. La vida de una mujer en una tierra inhóspita. Buenos Aires, Argentina: Ediciones B.

Cañuqueo, L., Kropff , L., \& Pérez, P. (2015). A la sombra del estado: Comunalización indígena en parajes de la pre cordillera de Río Negro, Argentina. Revista del Museo de Antropología, 8(2), 159-170.

Carricart, P. (2012). Cooperativas rurales y territorios en la región pampeana argentina. Transformaciones sociales, económicas y organizacionales. Buenos Aires, Argentina: La Colmena.

Comerci, M. E. (2010) "Tenemos que ir allá y pegar la vuelta". Continuidades y cambios en las prácticas de movilidad campesinas en contextos de conflictividad emergente. Transporte y Territorio, 3, 77-102.

Comerci M. E. (2013) Renovada expansión capitalista y vulnerable persistencia campesina en Argentina. En IV Congreso Nacional de Geografía, Mendoza.

Coronato, F. (2010). El rol de la ganadería ovina en la construcción del territorio de la Patagonia. (Tesis inédita de doctorado). Institut des Sciences et Industries du Vivant et de l'Environnement (Agro Paris Tech). Paris

Dirección de Ganadería de la Provincia de Chubut (2014). Estadística Ganadera. Cantidad de productores según zafra por departamento (2005-2014).

Durston, J. (2000). ¿Qué es el capital social comunitario? Serie Politicas Sociales, $N^{\circ}$ 38, Santiago de Chile: CEPAL.

Erbiti, C. (1996). El sistema de asentamientos. En Roccatagliata, J.A. (Coord.), Geografía Económica Argentina (96120). Buenos Aires: El Ateneo.

Escudero, H. B., \& Vazquez, A. D. (2014). Exploración metodológica: territorialidades y acceso a la atención de la salud en localidades patagónicas. En Diez Tetamanti, J. M. (Coord.), Hacia una geografía comunitaria: abordajes desde cartografía social y sistemas de información geográfica (45-62). Comodoro Rivadavia: Universitaria de la Patagonia EDUPA.

Foro Nacional de la Agricultura Familiar (FoNAF) (2006). Lineamientos generales de políticas públicas orientadas a la elaboración de un plan estratégico para la agricultura familiar. Documento de trabajo, Buenos Aires.

Gatica, C. (2016). La sustentabilidad ambiental en comunidades de pueblos originarios patagónicos en la actualidad. Aporte a partir del análisis de la Comunidad El Chalía. (Tesis inédita de licenciatura). Universidad Nacional de la Patagonia San Juan Bosco. Comodoro Rivadavia.

Haesbaert, R. (2013). Del mito de la desterritorialización a la multiterritorialidad. Revista Cultura $y$ Representaciones Sociales, 15, 9-42.

INDEC (1991). Censo Nacional de Población, Hogares y Viviendas.

INDEC (2001). Censo Nacional de Población, Hogares y 
Viviendas.

INDEC (2002). Censo Nacional Agropecuario.

INDEC (2010). Censo Nacional de Población, Hogares y Viviendas.

Marradi, A., Achenti, N., \& Piovani, J. I. (2010). Metodología de las Ciencias Sociales. Buenos Aires, Argentina: Cengage Learning Argentina.

Neiman, G., \& Quaranta, G. (2006). Los estudios de caso en la investigación sociológica. En Vasilachis de Gialdino,

I. (Coord.), Estrategias de investigación cualitativa (214-237). Barcelona, España: Gedisa.

Randle, P. (1972). Tipología del parcelamiento rural. GAEA Anales de la Sociedad Argentina de Estudios Geográficos, Tomo XV, 228-26.

Rodriguez, M. (2008). Camusu Aike: De la visibilización en los archivos a la re visibilización como comunidad. En III Jornadas de Historia de la Patagonia, Bariloche.

Rodriguez, M. (2010). De la "extinción" a la autoafirmación: procesos de visibilización de la comunidad tehuelche Camusu aike (provincia de santa cruz, argentina). (Tesis inédita de doctorado). Facultad de la Escuela de graduados de Artes y Ciencias de la Universidad de Georgetown. Washington DC.

Saenz Passeron, J. A. (2015). Territorio rural y sus transformaciones ante procesos de globalización en la subregión transandina de la Provincia de Palena, Patagonia chilena. (Tesis inédita de licenciatura). Universidad de Chile. Santiago de Chile.

Santos, M. (2000). La naturaleza del espacio. Técnica y tiempo. Razón y emoción. Barcelona: Ariel.

Scheinkerman de Obschatko, E. (2009). Las explotaciones agropecuarias familiares en la República Argentina: un análisis a partir de los datos del Censo Nacional Agropecuario 2002. Buenos Aires: Ministerio de Agricultura, Ganadería y Pesca de la Nación - Instituto Interamericano de Cooperación para la Agricultura.

Sili, M. (2007). Fragmentación territorial y desarrollo rural. Nuevas interpretaciones y propuestas para el desarrollo de los territorios rurales en un contexto de globalización. Serie Desarrollo Sustentable, Documento de trabajo $\mathrm{N}^{\circ} 1$.

Silveira, M. L. (2009). Región y división territorial del trabajo: desafíos en el período de globalización. Investigación y desarrollo, 17 (2), 435-455.

Tsakoumagkos, P. (2014) El trabajo agrario en la agricultura familiar de la Argentina - aproximaciones conceptuales. RED Sociales, 1, 2-18.

Vasilachis de Gialdino, I. (2006). La investigación cualitativa. En Vasilachis de Gialdino, I. (Coord.), Estrategias de investigación cualitativa (23-64). Barcelona, España: Gedisa.

Vazquez, A. D., \& Novara, M. (2012). Uso del suelo de la meseta central santacruceña: Análisis espacial mediante FOSS SIG y aportes para el fortalecimiento del sector ganadero. Revista Geografía y Sistemas de Información Geográfica, 4, 120-136.

Vazquez, A. D. (2014). Territorialidades y fragmentación rural en espacios patagónicos. En Juan Manuel Diez Tetamanti (Coord.). Hacia una geografía comunitaria: abordajes desde cartografía social y sistemas de información geográfica (85-95). Comodoro Rivadavia, Argentina: Universitaria de la Patagonia EDUPA. 